\title{
Chlorination of Isatins with Trichloroisocyanuric Acid
}

\author{
Bárbara V. Silva,* Pierre M. Esteves and Angelo C. Pinto \\ Instituto de Química-CT, Universidade Federal do Rio de Janeiro, Cidade Universitária, \\ 21945-970 Rio de Janeiro-RJ, Brazil
}

\begin{abstract}
A isatina e seus derivados são conhecidos na literatura por possuírem uma diversidade de propriedades biológicas. O método de Sandmeyer é o mais utilizado para síntese de diferentes isatinas substituídas, geralmente com altos rendimentos. Apesar de eficiente, este método apresenta algumas limitações, tais como a formação de uma mistura de regioisômeros e baixos rendimentos dependendo do tipo e posição do substituinte presente no material de partida, a anilina. Para superar estas limitações, é preferível que alguns derivados de isatina sejam obtidos por métodos alternativos. Este artigo descreve a cloração de derivados da isatina empregando ácido tricloroisocianúrico [1,3,5-tricloro-1,3,5-triazina-2,4,6- $(1 \mathrm{H}, 3 \mathrm{H}, 5 \mathrm{H})$-triona ou TCCA) em diferentes condições reacionais.
\end{abstract}

Isatin and its derivatives have been extensively reported in the literature as having range of potential pharmacological compounds. The Sandmeyer method is the most widely used for isatin synthesis and furnishes different substituted isatins, usually with high yields. Although efficient, the Sandmeyer route has certain limitations, such as the formation of a mixture of regiosiomers and low yields depending on the type and position of the substituent. Thus, overcome these limitations, it is preferable that some derivative isatins be obtained by alternative methods. This article has investigated the chlorination of isatin derivatives using trichloroisocyanuric acid [1,3,5-trichloro1,3,5-triazine-2,4,6-(1H,3H,5H)-trione or TCCA] at different reaction conditions.

Keywords: isatin, trichloroisocyanuric acid, chlorination

\section{Introduction}

Isatin is a natural compound found in plants of the genus Isatis $^{1}$ and in mammalian body fluids and tissues. This compound is distributed throughout the central nervous system and may be an endogenous modulator of food intake..$^{2-4}$

Isatin and its derivatives have been reported to possess antiviral, antinflammatory, antitumoral, anticonvulsant and sedative-hypnotic activities, ${ }^{5-8}$ and can be considered as versatile buildings blocks for the synthesis of a variety of pharmacologically active compounds.

The Sandmeyer method is the most common route to prepare isatins. ${ }^{9}$ Despite its efficiency this method has some limitations, such as the formation of a mixture of regioisomers ${ }^{10}$ and low yields, depending on the type and position of the substituent. But it fails whenever the isonitrosoacetanilides bearing electrodonating groups is used. In this case ring sulfonation occurs instead. ${ }^{11}$

*e-mail: barbara.iq@gmail.com
We have recently developed a new, efficient and fast methodology for the preparation of methoxyisatins in the presence of Lewis or Brønsted acids catalysts in different imidazolium based ionic liquids. ${ }^{12}$

In continuation to our interest in the synthesis of chloroisatins, we describe herein the study of the chlorination of several substituted isatins with trichloroisocyanuric acid (TCCA). ${ }^{13}$

\section{Results and Discussion}

The aromatic chlorination of the isatin with trichloroisocyanuric acid (TCCA) using sulfuric acid as a catalyst, was previously studied, ${ }^{14,15}$ which showed the formation of 5-chloroisatin and 5,7-dichloroisatin in excellent yields. Therefore, we started our investigation reacting the 5-methylisatin (1), a monosubstituted derivative, with TCCA in sulfuric acid $\left(\mathrm{H}_{2} \mathrm{SO}_{4}\right)$. In this condition, we found the formation of polychlorinated products (Scheme 1), using molar ratio between (1) and TCCA 1:0.4, 1:1 and 1:1.5. 


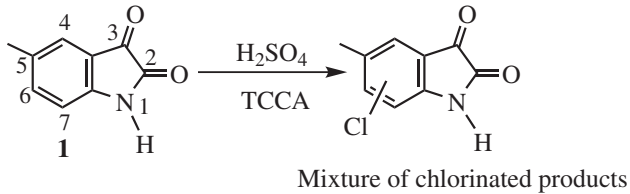

Scheme 1. Chlorination of (1) with TCCA in $\mathrm{H}_{2} \mathrm{SO}_{4}$.

Thus, we have replaced the $\mathrm{H}_{2} \mathrm{SO}_{4}$ by acetic acid (HOAc) in order to get a milder reaction conditions. The chlorination of (1), in HOAc, varying time and proportion isatin:TCCA furnished product $N$-chlorinated (1a) at different rates (Table 1).

Table 1. Chlorination of (1) with TCCA in HOAc<smiles>Cc1ccc2c(c1)C(=O)C(=O)N2OC(=O)O</smiles>

\begin{tabular}{lcccc}
\hline entry & Isatin:TCCA & Temperature $\left({ }^{\circ} \mathrm{C}\right)$ & time $(\mathrm{h})$ & GC Conversion $^{\mathrm{a}}$ \\
\hline 1 & $1: 0.5$ & 25 & 0.5 & $46 \%$ \\
2 & $1: 1$ & 25 & 2 & $79 \%$ \\
3 & $1: 2$ & 25 & 1 & $82 \%$ \\
4 & $1: 2$ & 25 & 2 & $69 \%$ \\
5 & $1: 2$ & 25 & 6 & $74 \%$ \\
6 & $1: 2$ & $80-90$ & 1 & $59 \%$ \\
7 & $1: 2.5$ & 25 & 0.5 & $76 \%$ \\
8 & $1: 2.5$ & 25 & 1 & $78 \%$ \\
9 & $1: 2.5$ & 25 & 6 & $78 \%$ \\
\hline
\end{tabular}

${ }^{\mathrm{a}} \mathrm{Gas}$ chromatograph equipped with a flame ionization detector. Approximately $1 \mu \mathrm{L}$ of sample was injected with a split ratio of $1 / 20$, column DB-5. Initial temperature was $100{ }^{\circ} \mathrm{C}$ at $12{ }^{\circ} \mathrm{C} \mathrm{min}{ }^{-1}$ until $210{ }^{\circ} \mathrm{C}$ for $10 \mathrm{~min}$. The injector and detector temperature was $280^{\circ} \mathrm{C}$.

As seen in the Table 1, using the proportion TCCA 1:0.5 (entry 1), the conversion was $46 \%$. The decrease of the molar ratio (entry 2) leads to an increase in the conversion.

To obtain higher conversions, the molar ratio 1:2 was used, varying the temperature and the reaction time (entries 3-6). These experiments showed that increases in the molar ratio and time do not influence the conversion rate. However, higher temperature (entry 6) resulted in lower conversion compared with the experiment in entry 3 . The conversion does not change significantly with the increase of the molar ratio isatin:TCCA from 1:1 to 1:2.5 (entries 7-9).

Initially, the aromatic chlorination of (1) in position 7 , using HOAc as catalyst was expected. The analysis of the mass spectrum of the product (Figure 1) revealed the occurrence of $\mathrm{N}$-chlorination, rather than aromatic chlorination.

The reaction was also monitored by thin layer chromatography. The retention coefficient $\left(\mathrm{R}_{\mathrm{f}}\right)$ of the a)

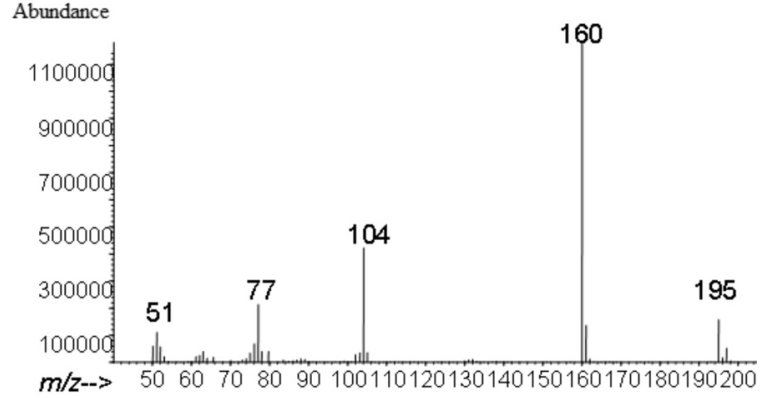

b)

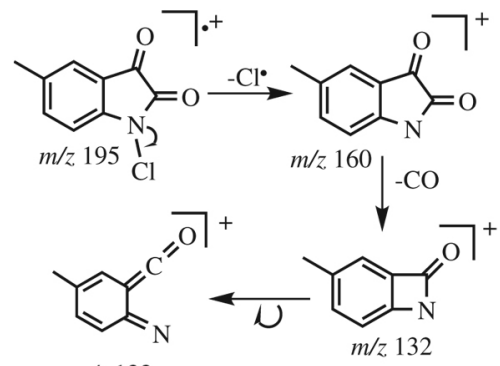<smiles>Cc1cccnc1C(C)(C)C(=O)O</smiles>

Figure 1. a) Mass spectra of $N$-chloro-5-methylisatin (1a); b) Proposal of fragmentation for the molecular ion of (1a).

compound $N$-chlorinated (0.48) is much higher than the substrate (0.24) using hexane/ethyl acetate $50 \%$ as eluent.

As the literature reported the $N$-chlorination of amides, carbamates and lactams with TCCA in acetone or chloroform, ${ }^{16}$ we have examined the application of theses solvents in the chlorination of (1) with molar ratio 1:2 (isatin:TCCA). The conversion in acetone was $84 \%$ and $74 \%$ in chloroform. These conversions were equivalent to those obtained with HOAc. Although the conversions are similar, the procedure using HOAc is simpler and faster, since the addition of ice to the reaction medium at the end of the reaction affords a precipitate, which is filtered off.

We have next tested the same reaction in HOAc with isatin derivatives (Scheme 2 and Table 2) and the fragmentation standard of the products obtained again<smiles>[R]c1cc([R2])c2c(c1)C(=O)C(=O)N2[R]</smiles>

$$
\begin{array}{ll}
\text { 2 } \mathrm{R}=\mathrm{H}, \mathrm{R}^{1}=\mathrm{Br}, \mathrm{R}^{2}=\mathrm{H} & \\
\text { 3 } \mathrm{R}=\mathrm{H}, \mathrm{R}^{1}=\mathrm{NO}_{2,} \mathrm{R}^{2}=\mathrm{H} & \text { 2a } \mathrm{R}=\mathrm{Cl}, \mathrm{R}^{1}=\mathrm{Br}, \mathrm{R}^{2}=\mathrm{H} \\
\mathbf{4} \mathrm{R}=\mathrm{H}, \mathrm{R}^{1}=\mathrm{H}, \mathrm{R}^{2}=\mathrm{CF}_{3} & \text { 5b } \mathrm{R}=\mathrm{H}, \mathrm{R}^{1}=\mathrm{Cl}, \mathrm{R}^{2}=\mathrm{CF}_{3} \\
\mathbf{5} \mathrm{R}=\mathrm{Me}, \mathrm{R}^{1}=\mathrm{H}, \mathrm{R}^{2}=\mathrm{H} & \text { 6b } \mathrm{R}=\mathrm{R}, \mathrm{R}^{2}=\mathrm{H} \\
\mathbf{6} \mathrm{R}=\mathrm{H}, \mathrm{R}^{1}=\mathrm{H}, \mathrm{R}^{2}=\mathrm{Me} & \mathrm{Me}
\end{array}
$$

Scheme 2. Chlorination reaction of isatin derivatives with TCCA in HOAc or acetone.. 
Table 2. Results of chlorination reaction of isatin derivatives with TCCA in HOAc or acetone

\begin{tabular}{|c|c|c|c|c|c|c|}
\hline entry & Isatin & Isatin:TCCA & Temperature $\left({ }^{\circ} \mathrm{C}\right)$ & time (h) & Solvent & GC Conversion $^{\mathrm{a}}$ \\
\hline 1 & 2 & $1: 0.5$ & 25 & 0.5 & HOAc & $44 \%$ \\
\hline 2 & 2 & $1: 1$ & 25 & 5 & HOAc & $45 \%$ \\
\hline 3 & 2 & $1: 2$ & 25 & 1 & HOAc & $61 \%$ \\
\hline 4 & 3 & $1: 2$ & 25 & 2 & HOAc & NR \\
\hline 5 & 4 & $1: 2$ & 25 & 2 & HOAc & NR \\
\hline 6 & 4 & $1: 2$ & $80-90$ & 1 & HOAc & $12 \%$ \\
\hline 7 & 5 & $1: 2$ & 25 & 2 & HOAc & $96 \%$ \\
\hline 8 & 5 & $1: 0.5$ & 25 & 2 & Acetone & $51 \%$ \\
\hline 9 & 5 & $1: 2$ & 25 & 2 & Acetone & $91 \%$ \\
\hline 10 & 6 & $1: 1$ & 25 & 1 & HOAc & $100 \%$ \\
\hline
\end{tabular}

Same conditions shown in the footnote of Table 1; NR: no reaction.

showed the $\mathrm{N}$-chlorination for isatin (2). Nitroisatin with the nitro group at position 5 (3) did not react. The deactivated isatin 4 reacted at higher temperature $\left(80-90{ }^{\circ} \mathrm{C}\right)$, but with low conversion. The fragmentation standard of (4b) revealed chlorination occurs at the aromatic ring. On the other hand $N$-methylisatin (5) and 7-methylisatin (6) gave excellent conversions (entries 7-10) at room temperature.

The fragmentation proposal of the product $(\mathbf{4 b})$ and (5b) is showed in Scheme 3.

The first report of $\mathrm{N}$-chlorination of isatins was done by Berti and Greci. ${ }^{17}$ They also used HOAc, but the

a)<smiles>CC[O+]=C1Nc2c(cc(Cl)cc2C(F)(F)F)C1=O</smiles>
$\mathrm{m} / \mathrm{z} 249$ $\mathrm{m} / \mathrm{z} 221$

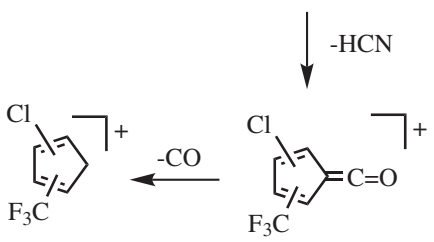
$m / 2.166$

$m / z, 194$

b)<smiles>CCOC(=O)c1ccc(Cl)cc1</smiles>

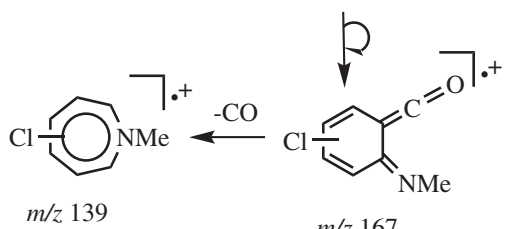
$m / z 167$

Scheme 3. Fragmentation proposal of (4b) (a) and (5b) (b). chlorination agent was $7 \%$ sodium hypochlorite $(\mathrm{NaClO})$. This reagent was described as a new convenient oxidant.

Whenever the isatin derivative presents a $\mathrm{NH}$ bond without substituent in position 7 , the $\mathrm{N}$-chlorination is favored (entries 1-3). The experiments carried out with the $N$-methylisatin (5) and 7-methylisatin (6) (entries 7-10) suggested that the use of acids promotes ring chlorination of isatin. Previous works showed that superelectrophiles could be involved in such processes. ${ }^{15}$

In order to better understand the chlorination process of isatins with TCCA, we have carried out DFT calculations, at M06-2x/6-311++G(d,p) level, for the chlorination of parent isatin by TCCA (see supporting information for computational details). Figure 2 shows the computed van der Waals complex between TCCA and isatin.

Despite the original configuration the outcome of the optimization of the geometry leads to a complex involving

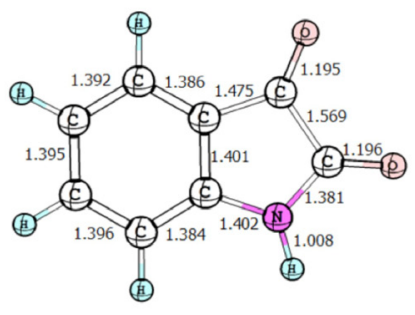

isatin

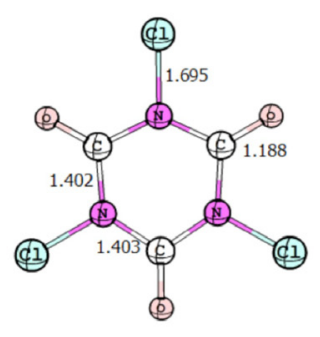

TCCA

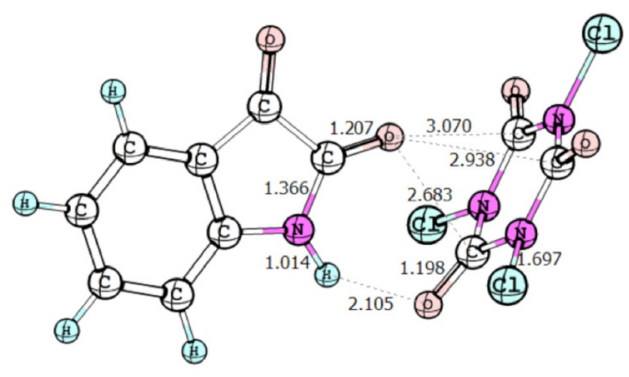

isatin-TCCA complex
Figure 2. Optimized geometries for isatin TCCA and a complex between them, calculated at M06-2X/6-311++G(d,p). 


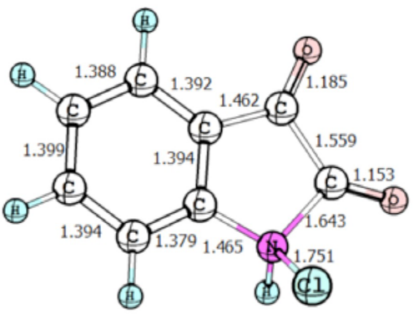

A $\Delta \mathrm{H}_{\text {rel }}=23.4 \mathrm{kcal} \mathrm{mol}^{-1}$

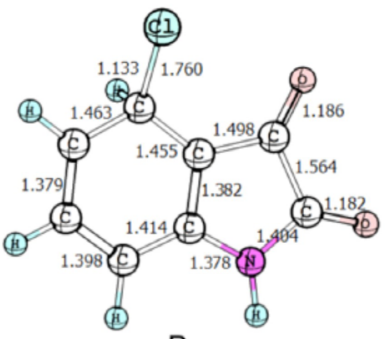

$\mathrm{B}$

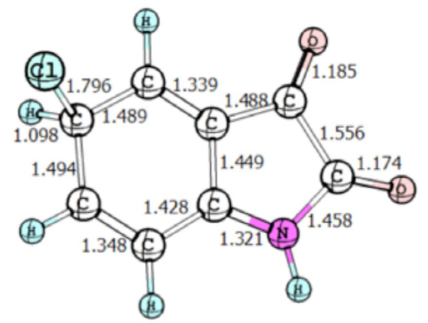

$\mathrm{C}$ $\Delta \mathrm{H}_{\mathrm{rel}}=25.3 \mathrm{kcal} \mathrm{mol}^{-1}$
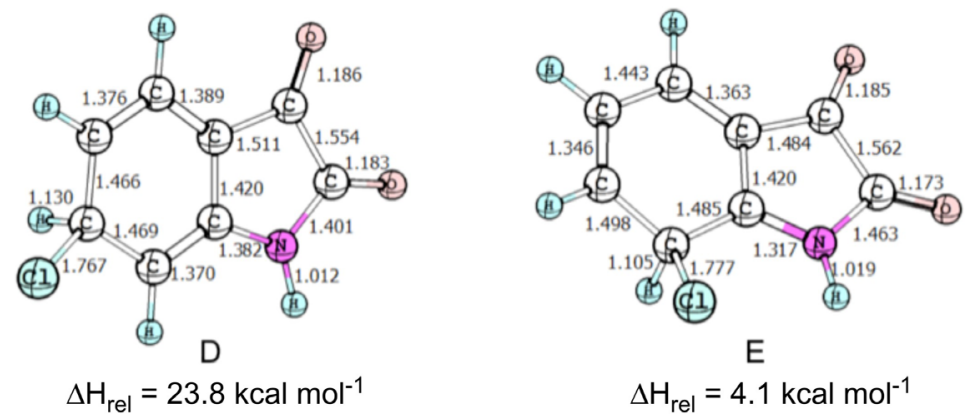

Figure 3. Optimized geometries for the intermediates formed from the attack of $\mathrm{Cl}^{+}$of isatin, calculated at M06-2X/6-311++G(d,p).

the $\mathrm{N}-\mathrm{H}$ and the carbonyl group of the isatin. This complex is $2.4 \mathrm{kcal} \mathrm{mol}^{-1}$ more stable in relation to the separated isatin and TCCA. The amide carbonyl group pointing into the TCCA ring indicates that this complex can be a donor-acceptor complex. Thus, this preliminary complex can lead to the preferred formation of the $N$-chloroisatin. For this purpose we have computed the relative stability of the several intermediates formed through the electrophilic addition of $\mathrm{Cl}^{+}$to isatin. Figure 3 presents these structures, with their relative energies.

It can be seen from the calculations that the most stable intermediate is $\mathrm{C}$. The $\mathrm{N}$-chlorination of the isatin leads to intermediate $\mathrm{A}$, which is $23.4 \mathrm{kcal} \mathrm{mol}^{-1}$ higher in energy than $\mathrm{C}$. This indicates that the $\mathrm{N}$-chlorination should be a kinetically driven process. Considering that the relative stability of the arenium ions reflect the relative stability in the transition state prior to them, it can be seen that the pattern for the ring substitution is followed, i.e., ortho-para substituion in relation to the nitrogenated substituent.

Because of the possibility of involvement of superelectrophiles in the process when the reaction takes place at more acid solvents, we decided to go back to our investigations for the chlorination of some isatin derivatives in concentrated $\mathrm{H}_{2} \mathrm{SO}_{4}$. The results are showed in Table 3 .

When the isatins reacts in the presence of $\mathrm{H}_{2} \mathrm{SO}_{4}$ the aromatic ring chlorination always occurs. Conversely, in HOAc, the $N$-chlorination takes place. In order to explain this result, we proceeded to the following experiment: (1a), the 5-methyl- $N$-chloroisatin obtained from the reaction of 5-methylisatin (1) in HOAc, was treated with $\mathrm{H}_{2} \mathrm{SO}_{4}$ concentrated and stirred at room temperature for $4 \mathrm{~h}$. After this period, ice was added to the reaction medium and the solid precipitate was filtered under vacuum and analyzed by gas chromatography mass spectrometry (GC-MS). The chromatogram and mass spectrum showed that under this condition, the reaction furnished a mixture of mono and dichlorinated products in the aromatic ring.

Therefore, we conclude that the $N$-chlorinated product should be formed as an intermediate for the reaction of chlorination in the aromatic ring. Once the acetic acid is not acid enough for lead to further protonate this chlorinated intermediate, the transfer of " $\mathrm{Cl}^{+"}$ " probably becomes difficult. Further evidence that the $N$-chlorinated isatin is actually a reaction intermediate is the tendency of the $\mathrm{N}$-chloroisatins have of turning, in a few days, into their respective parent isatins. In order to confirm the formation of $\mathrm{N}$-chlorinated compound and its reactivity toward other nucleophiles, an experiment of chlorination of anisole was performed, using isatin (1a) in HOAc. The products were analyzed by GC-MS and showed the formation of mono and dichlorinated methoxybenzene and isatin (1).

The halogens $\mathrm{Br}$ and $\mathrm{F}$ are weak electron withdrawing groups. Thus, the isatin (2) and (7) had their aromatic rings (entries 2 and 4 ) chlorinated only at position 7 with molar ratio isatin:TCCA 1:1.

The trifluoromethyl group strongly deactivates the aromatic ring for electrophilic substitution aromatic and no product was formed in an attempt to chlorination isatin (4) at room temperature (entry 3 ). 
Table 3. Chlorination of isatin derivatives with TCCA in concentrated $\mathrm{H}_{2} \mathrm{SO}_{4}$ at room temperature

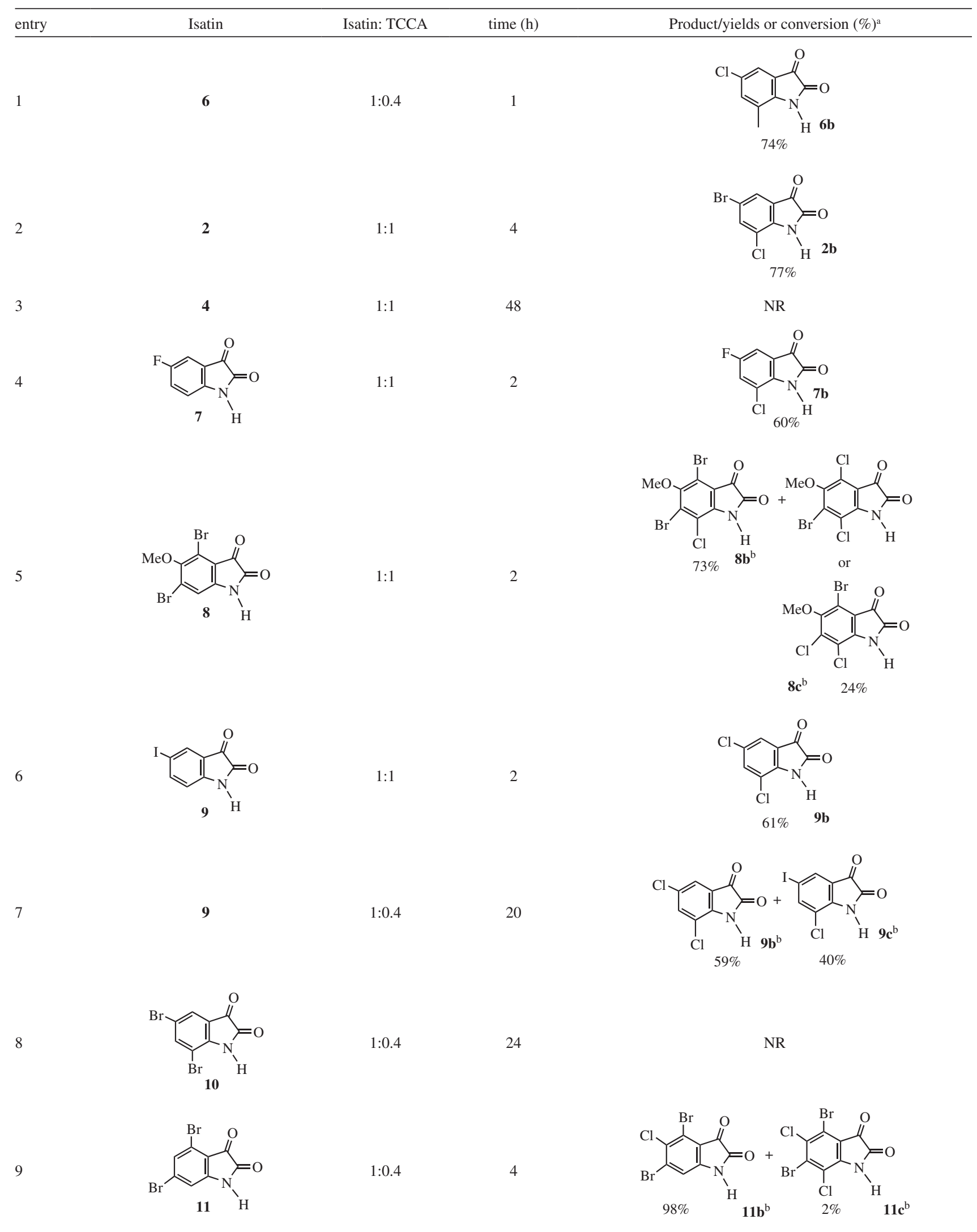




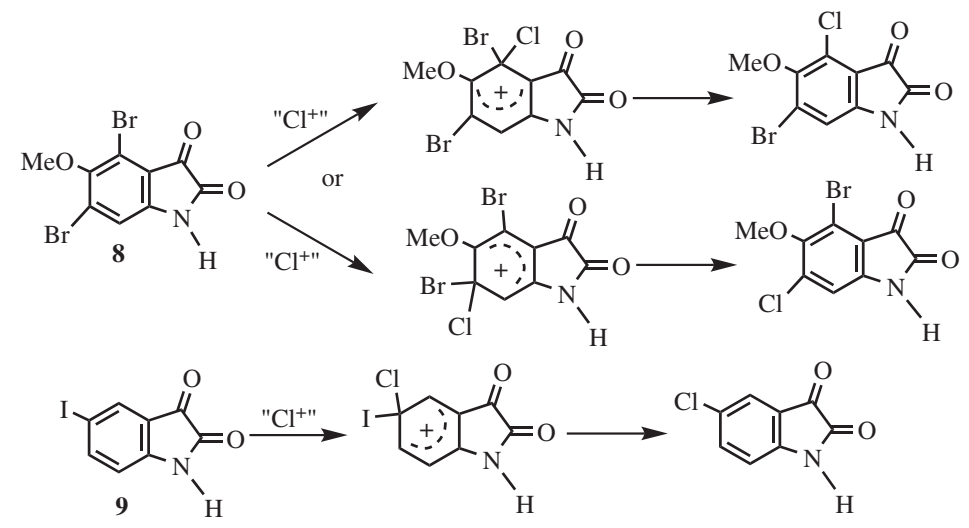

Scheme 4. Mechanism of ipso substitution for isatin (8) and (9).

Ipso substitution on the aromatic ring was observed in isatins (8) and (9) (entries 5-7) (Scheme 4). Reaction with isatin $(\mathbf{8})$ resulted in mixture of products. The product $(\mathbf{8 b})$ was expected (substitution at position 7) and product (8c) resulted from the ipso substitution at position 4 or 6 .

Isatin (9) suffered cleavage of C-I bond furnishing product $(\mathbf{9 b})$, substituted in positions 5 and 7 , when the molar ratio isatin:TCCA was 1:1. Mixture of products was obtained when the molar ratio was decreased to 1:0.4. In this case an ipso substitution also occurs providing the product (9b) and a common electrophilic aromatic substituition conducted to new product (9c) in 59\% conversion.

Since we found that the substitution at the ipso position competes with the unsubstituted positions when the isatin has a bromine atom, we have investigated the same reaction with isatins (10) and (11) (entries 8 e 9). We could not detect products coming from ipso substitution in such cases. Isatin (10) did not react and isatin (11) resulted in substitution at positions 5 and 7 , as expected.

The electron donating methoxy group in isatin (8) is probably, essential for the ipso substitution. For the isatin (9), the substitution at ipso position can be explained in terms of the high lability of the $\mathrm{C}-\mathrm{I}$ bond.

\section{Conclusions}

In conclusion, we performed a study on the behavior of substituted isatins in $\mathrm{H}_{2} \mathrm{SO}_{4}$ and $\mathrm{HOAc}$ with TCCA. In HOAc we found that the formation of $N$-chlorinated products occurs at different reaction conditions since the isatin nitrogen has not replaced by a methyl group or a substituent in position 7. In $\mathrm{H}_{2} \mathrm{SO}_{4}$ always occurs the chlorination of the aromatic ring. The methyl group in position 5 strongly activates the aromatic ring, resulting in a mixture of chlorinated products when the substrate is 5-methylisatin (1). Isatins with substituents electron withdrawing yield 1 product, except when there was competition for ipso substitution. The proposed methodology furnished the new pure compound (2b) and mixture of products also not previously reported in the literature, $(\mathbf{8 b}),(\mathbf{8 c}),(\mathbf{9 c}),(\mathbf{1 1 b})$ and $(\mathbf{1 1 c})$. The substances already reported $(\mathbf{6 b})$ and $(\mathbf{7 b})$ were obtained pure. Thus, we have shown that TCCA, a non toxic and inexpensive reagent, is an interesting alternative for the preparation of chlorinated isatins.

\section{Supplementary Information}

Supplementary information associated with this paper contains the spectroscopic data, NMR spectra $\left({ }^{1} \mathrm{H}\right.$ and $\left.{ }^{13} \mathrm{C}\right)$, mass spectrum and infrared of the synthesized compounds. These data are available free of charge at http://jbcs.sbq. org.br, as a PDF file.

\section{Acknowledgments}

The authors thank the Brazilian agencies Conselho Nacional de Desenvolvimento Científico e Tecnológico (CNPq) and Fundação de Amparo à Pesquisa do Estado do Rio de Janeiro (FAPERJ).

\section{References}

1. Guo, Y.; Chen, F.; Zhongcaoyao 1986, 17, 8. (CA 104:213068f).

2. Tozawa, Y.; Ueki, A; Manabe, S.; Matsushima, K.; Biochem. Pharmacol. 1998, 56, 1041.

3. Glover, V.; Bhattacharya, S. K.; Chakrabarti, A.; Sandler, M.; Stress Med. 1998, 14, 224.

4. Morley, J. E.; Farr, S. A.; Flood, J. F.; Eur. J. Pharm. 1996, 305, 23.

5. Vine, K. L.; Matesic, L.; Locke, J. M.; Ranson, M.; Skropeta, D.; Anti-Cancer Agents Med. Chem. 2009, 9, 397.

6. Silva, J. F. M.; Garden, S. J.; Pinto, A. C.; J. Braz. Chem. Soc. 2001, 12, 273. 
7. Hall, M. D.; Salam, N. K.; Hellawell, J. L.; Fales, H. M.; Kensler, C. B.; Ludwig, J. A.; Szakács, G.; Hibbs, D. E.; Gottesman, M. M.; J. Med. Chem. 2009, 52, 3191.

8. Zapata-Sudo, G.; Pontes, L. B.; Gabriel, D.; Mendes, T. C. F.; Ribeiro, N. M.; Pinto, A. C.; Trachez, M. M.; Sudo, R. T.; Pharmacol., Biochem. Behav. 2007, 86, 678.

9. Sandmeyer, T.; Helv. Chim. Acta 1919, 2, 234.

10. Almeida, M. R.; Leitão, G. G.; Silva, B. V.; Barbosa, J. P.; Pinto, A. C.; J. Braz. Chem. Soc. 2010, 21, 764.

11. Prinz, W.; Kaile, A.; Levy, P. R.; J. Chem. Res. (S) 1978, 116; Prinz, W.; Kaile, A.; Levy, P. R.; J. Chem. Res. (M) 1978, 1347.

12. Pinto, A. C.; Lápis, A. A. M.; Silva, B. V.; Bastos, R. S.; Dupont, J.; Neto, B. A. D.; Tetrahedron Lett. 2008, 49, 5639.
13. Vasconcellos, M. L. A. A.; Junior, C. G. L.; Quim. Nova 2009, 32, 244; Mendonça, G. F.; Mattos, M. C. S.; Quim. Nova 2008, 31, 798; Cunha, A. C.; Paixão, F. M.; Souza, M. C. B. V.; Ferreira, V. F. Quim. Nova 2006, 29, 520; Bastos, R. S.; Cunha, A. S.; Silva, L. C.; Oliveira, C. C. P.; Rezende, C. M.; Pinto, A. C.; Quim Nova, 2008, 31, 172; Barros, J. C.; Synlett 2005, 13, 2115.

14. Ribeiro, N. M.; Silva, B. V.; Violante, F. A.; Rezende, C. M.; Pinto, A. C.; Org. Prep. Proced Int. 2005, 37, 265.

15. Mendonça, G. F.; Magalhães, R. R.; Mattos, M. C. S.; Esteves, P. M.; J. Braz. Chem. Soc. 2005, 16, 695.

16. De Luca, L.; Giacomelli, G.; Nieddu, G.; Synlett 2005, 223.

17. Berti, C.; Greci, L.; Synth. Commun. 1981, 11, 681.

Submitted: June 5, 2010 Published online: September 21, 2010 


\title{
Chlorination of Isatins with Trichloroisocyanuric Acid
}

\author{
Bárbara V. Silva,* Pierre M. Esteves and Angelo C. Pinto \\ Instituto de Química-CT, Universidade Federal do Rio de Janeiro, Cidade Universitária, \\ 21945-970 Rio de Janeiro-RJ, Brazil
}

Synthesis and characterization of the chloroisatins

Typical procedure for the reaction in $\mathrm{HOAc}$

To a suspension of TCCA and HOAc the isatin derivative was added. The reaction medium was kept stirring at different temperatures and times (Tables 1 and 2). The mixture was then poured over cracked ice. The precipitate was filtered under vacuum and washed thoroughly with water. Subsequently, the product was solubilized in ethyl acetate, filtered and the solution evaporated at reduced pressure to separate the isocyanuric acid formed as byproduct.

Typical procedure for the reaction in $\mathrm{H}_{2} \mathrm{SO}_{4}$

To a suspension of TCCA and $\mathrm{H}_{2} \mathrm{SO}_{4}$ was added the isatin derivative in an ice bath. After the complete addition of the isatin, the ice bath was removed, and the mixture was kept stirring during the time described in Table 3 . The mixture was then poured over cracked ice. The precipitate was filtered under vacuum and washed thoroughly with water. Subsequently, the product was solubilized in ethyl acetate, filtered and the solution evaporated at reduced pressure to separate the isocyanuric acid formed as byproduct. The products $(\mathbf{9 b})$ and $(\mathbf{9 c})$ were separated by high performance liquid chromatography (HPLC) and analyzed separately by ${ }^{1} \mathrm{H}$ and ${ }^{13} \mathrm{C}$ NMR.

\section{Separation by HPLC}

Separation by HPLC of $(\mathbf{9 b})$ and $(\mathbf{9 c})$ was performed on Agilent 1100 series chromatograph detection by ultraviolet (UV, $\lambda_{\max } / \mathrm{nm} 280$ ). Semi-preparative method in a reversed phase column C-18 (Agilent Zorbax Eclipse, $9.4 \mathrm{~mm}$ (diameter) $\times 250 \mathrm{~mm}$ (length), 5 micron) under isocratic conditions using $45 \%$ water and $55 \%$ methanol as mobile phase, flow $3 \mathrm{~mL} / \mathrm{min}$, with $30 \mathrm{~min}$ elution was employed.

*e-mail: barbara.iq@gmail.com

\section{Computational details}

All calculations were carried out with the Gaussian 09 package $^{1}$ using the M06-2X functional with the $6-311++\mathrm{G}^{* *}$ basis set. The optimized geometries were characterized as minima on the potential energy surface by the absence of imaginary vibrational frequencies. All energy differences correspond to enthalpies differences at 298K and $1 \mathrm{~atm}$.

\section{Spectroscopic data}

1a: IR (film) $v_{\max } / \mathrm{cm}^{-1}: 3085,2923,1764,1729,1614$, 1596, 1483, 1315, 1294, 1176, 1126, 950, 427. 'H NMR $\delta\left(200 \mathrm{MHz}, \mathrm{CDCl}_{3}\right): 3.23(3 \mathrm{H}, \mathrm{s}), 6.85(1 \mathrm{H}, \mathrm{d}, J 8.0 \mathrm{~Hz})$, 7.51-7.57 (2H, m); ${ }^{13} \mathrm{C}$ NMR $\delta\left(50 \mathrm{MHz}, \mathrm{CDCl}_{3}\right): 26.5$ $\left(\mathrm{CH}_{3}\right), 111.4(\mathrm{CH}), 118.3(\mathrm{q}), 125.2(\mathrm{CH}), 129.7(\mathrm{q}), 137.9$ (CH), 149.8 (q), 157.8 (q), 182.4 (q); MS (70 eV) $\mathrm{m} / z .195$ $[\mathrm{M}]^{+}, 197[\mathrm{M}+2]^{+}, 160,104$.

2a: IR (film) $v_{\max } / \mathrm{cm}^{-1}: 3060,1770,1743,1606,1456$, $1423,1307,1270,1178,1160,827,717,466 .{ }^{1} \mathrm{H}$ NMR $\delta(200$ $\left.\mathrm{MHz}, \mathrm{CDCl}_{3}\right): 7.07(1 \mathrm{H}, \mathrm{d}, J 8.0 \mathrm{~Hz}), 7.71(1 \mathrm{H}, \mathrm{d}, J 2.0 \mathrm{~Hz})$, $7.81(1 \mathrm{H}, \mathrm{dd}, J 2.0$ and $8.0 \mathrm{~Hz}) ;{ }^{13} \mathrm{C}$ NMR $\delta(50 \mathrm{MHz}$, $\left.\mathrm{CDCl}_{3}\right): 113.0(\mathrm{CH}), 118.0(\mathrm{q}), 120.5(\mathrm{q}), 127.9(\mathrm{CH}), 141.2$

1. Frisch, M. J.; Trucks, G. W.; Schlegel, H. B.; Scuseria, G. E.; Robb, M. A.; Cheeseman, J. R.; Scalmani, G.; Barone, V.; Mennucci, B.; Petersson, G. A.; Nakatsuji, H.; Caricato, M.; Li, X.; Hratchian, H. P.; Izmaylov, A. F.; Bloino, J.; Zheng, G.; Sonnenberg, J. L.; Hada, M.; Ehara, M.; Toyota, K.; Fukuda, R.; Hasegawa, J.; Ishida, M.; Nakajima, T.; Honda, Y.; Kitao, O.; Nakai, H.; Vreven, T.; Montgomery, Jr., J. A.; Peralta, J. E.; Ogliaro, F.; Bearpark, M.; Heyd, J. J.; Brothers, E.; Kudin, K. N.; Staroverov, V. N.; Kobayashi, R.; Normand, J.; Raghavachari, K.; Rendell, A.; Burant, J. C.; Iyengar, S. S.; Tomasi, J.; Cossi, M.; Rega, N.; Millam, N. J.; Klene, M.; Knox, J. E.; Cross, J. B.; Bakken, V.; Adamo, C.; Jaramillo, J.; Gomperts, R.; Stratmann, R. E.; Yazyev, O.; Austin, A. J.; Cammi, R.; Pomelli, C.; Ochterski, J. W.; Martin, R. L.; Morokuma, K.; Zakrzewski, V. G.; Voth, G. A.; Salvador, P.; Dannenberg, J. J.; Dapprich, S.; Daniels, A. D.; Farkas, O.; Foresman, J. B.; Ortiz, J. V.; Cioslowski, J.; Fox, D. J.; Gaussian 03, Revision C.02, Gaussian, Inc.: Wallingford CT, 2004. 
$(\mathrm{CH}), 148.0$ (q), 154.7 (q), 176.8 (q), 182.4 (q); MS (70 eV) $m / z, 259[\mathrm{M}]^{+}, 261,[\mathrm{M}+2]^{+}, 263[\mathrm{M}+3]^{+}, 168,226$.

2b: IR (film) $v_{\max } / \mathrm{cm}^{-1}: 3471,3174,3110,1754,1610$, $1457,1425,1290,1224,1168,837 ;{ }^{1} \mathrm{H}$ NMR $\delta(200 \mathrm{MHz}$, $\left.\mathrm{CDCl}_{3}+\mathrm{DMSO}\right): 7.47(1 \mathrm{H}, \mathrm{s}), 7.58(1 \mathrm{H}, \mathrm{s}), 11.43(1 \mathrm{H}, \mathrm{br}$ s, NH); ${ }^{13} \mathrm{C}$ NMR $\delta\left(50 \mathrm{MHz}, \mathrm{CDCl}_{3}+\mathrm{DMSO}\right): 114.8$ (q), 118.2 (q), 119.5 (q), $125.5(\mathrm{CH}), 139.1(\mathrm{CH}), 146.8(\mathrm{q})$, 158.3 (q), 182.1 (q); $\mathrm{MS}(70 \mathrm{eV}) \mathrm{m} / \mathrm{z} 259[\mathrm{M}]^{+}, 261,[\mathrm{M}+2]^{+}$, $263[\mathrm{M}+3]^{+}, 233,205$.

5b: IR (film) $v_{\text {max }} / \mathrm{cm}^{-1}: 3467,3423,1751,1727,1608$, $1457,1467,1326,1176,1108,827 ;{ }^{1} \mathrm{H}$ NMR $\delta(200 \mathrm{MHz}$, $\left.\mathrm{CDCl}_{3}+\mathrm{DMSO}\right): 3.16(3 \mathrm{H}, \mathrm{s}), 6.89(1 \mathrm{H}, \mathrm{d}, J 8.0 \mathrm{~Hz})$, $7.43(1 \mathrm{H}, \mathrm{s}), 7.52(1 \mathrm{H}, \mathrm{d}, J 8.0 \mathrm{~Hz}), 11.43(1 \mathrm{H}, \mathrm{br} \mathrm{s}, \mathrm{NH})$; ${ }^{13} \mathrm{C}$ NMR $\delta\left(50 \mathrm{MHz}, \mathrm{CDCl}_{3}+\mathrm{DMSO}\right): 25.4\left(\mathrm{CH}_{3}\right), 116.6$ $(\mathrm{CH}), 123.1(\mathrm{q}), 129.5(\mathrm{CH}), 134.0(\mathrm{q}), 142.6(\mathrm{CH}), 154.6$ (q), 162.6 (q), 187.3 (q); MS (70 eV) m/z $195[\mathrm{M}]^{+}, 197$ $[\mathrm{M}+2]^{+}, 167,139$.

6b: IR (film) $\mathrm{v}_{\max } / \mathrm{cm}^{-1}: 3452,3415,3178,3102$, $1743,1616,1469,1297,889,700 ;{ }^{1} \mathrm{H}$ NMR $\delta(200$ $\left.\mathrm{MHz}, \mathrm{CDCl}_{3}+\mathrm{DMSO}\right): 2.15$ (3H, s), 7.20 (1H, br s), 7.27 $(1 \mathrm{H}$, br s$), 11.13(1 \mathrm{H}$, br s, NH$) ;{ }^{13} \mathrm{C}$ NMR $\delta(50 \mathrm{MHz}$, $\left.\mathrm{CDCl}_{3}+\mathrm{DMSO}\right): 14.2\left(\mathrm{CH}_{3}\right), 117.0(\mathrm{q}), 120.3(\mathrm{CH}), 122.8$ (q), $126.3(\mathrm{CH}), 137.2(\mathrm{CH}), 146.9$ (q), $158.3(\mathrm{q}), 182.6$ (q); MS (70 eV) m/z $195[\mathrm{M}]^{+}, 197[\mathrm{M}+2]^{+}, 167,139,104$. 7b: IR (film) $v_{\max } / \mathrm{cm}^{-1}: 3488,3473,3180,3114,1743$, 1754, 1621, 1600, 1479, 1299, 1211, 1099, 925, 867, 796; ${ }^{1} \mathrm{H}$ NMR $\delta\left(200 \mathrm{MHz}, \mathrm{CDCl}_{3}+\mathrm{DMSO}\right): 6.92(1 \mathrm{H}, \mathrm{d}$ $J 7.0 \mathrm{~Hz}), 7.04(1 \mathrm{H}, \mathrm{d} J 7.0 \mathrm{~Hz}), 11.04(1 \mathrm{H}$, br s, $\mathrm{NH}) ;{ }^{13} \mathrm{C}$ NMR $\delta\left(50 \mathrm{MHz}, \mathrm{CDCl}_{3}+\mathrm{DMSO}\right): 110.1(\mathrm{CH} \mathrm{d} J 27 \mathrm{~Hz})$, 117.7 (q, d J 7.0 Hz), 118.6 (q, d, J 7.0 Hz) $124.4(\mathrm{CH}, \mathrm{d}$, $J 27 \mathrm{~Hz}), 144.3(\mathrm{q}, \mathrm{d}, J 2.5 \mathrm{~Hz}), 157.7$ (q, d, $J 246.5 \mathrm{~Hz}$ ), 158.9 (q), 182.8 (q, d $J 2.5 \mathrm{~Hz})$. MS (70 eV) $\mathrm{m} / z .199$ [M]', $201[\mathrm{M}+2]^{+}, 171,143$.

9c: IR (film) $v_{\text {max }} / \mathrm{cm}^{-1}: 3193,3182,3099,1770,1745$, 1610, 1450, 1164, 983, 688; ${ }^{1} \mathrm{H}$ NMR $\delta(200 \mathrm{MHz}$, $\left.\mathrm{CDCl}_{3}+\mathrm{DMSO}\right): 7.71(1 \mathrm{H}, \mathrm{d} J 1.5 \mathrm{~Hz}), 7.77(1 \mathrm{H}, \mathrm{d}$ $J 1.5 \mathrm{~Hz}), 10.78\left(1 \mathrm{H}\right.$, br s, NH); ${ }^{13} \mathrm{C}$ NMR $\delta(50 \mathrm{MHz}$, $\mathrm{CDCl}_{3}+\mathrm{DMSO}$ ): 84.79 (q), 118.97 (q), 120.36 (q), 132.03 (CH), 145.34 (CH), 147.48 (q), 158.23 (q), 182.14 (q); MS $(70 \mathrm{eV}) \mathrm{m} / z, 307[\mathrm{M}]^{+}, 309[\mathrm{M}+2]^{+}, 279,251$.

11b: IR (film) $v_{\max } / \mathrm{cm}^{-1}: 3479,3465,3268,3087$, 1766, 1791, 1594, 1558, 1388, 1247, 958; ${ }^{1} \mathrm{H}$ NMR $\delta$ (200 MHz, $\left.\mathrm{CDCl}_{3}+\mathrm{DMSO}\right): 6.29(1 \mathrm{H}, \mathrm{s}), 10.40(1 \mathrm{H}, \mathrm{br} \mathrm{s}$, $\mathrm{NH}) ;{ }^{13} \mathrm{C}$ NMR $\delta\left(50 \mathrm{MHz}, \mathrm{CDCl}_{3}+\mathrm{DMSO}\right): 114.3(\mathrm{CH})$, 118.7 (q), 126.3 (q), 127.8 (q), 129.5 (q), 148.6 (q), 156.4 (q), 178.5 (q); MS (70 eV) m/z $337[\mathrm{M}]^{+}, 339[\mathrm{M}+2]^{+}, 341$ $[\mathrm{M}+3]^{+}, 343[\mathrm{M}+4]^{+}, 311,284,204$.

${ }^{1} \mathrm{H}$ and ${ }^{13} \mathrm{C}$ NMR spectra

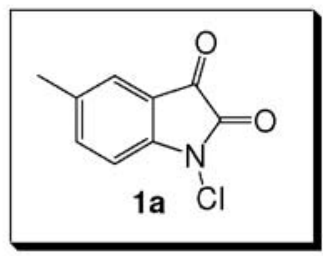

1a
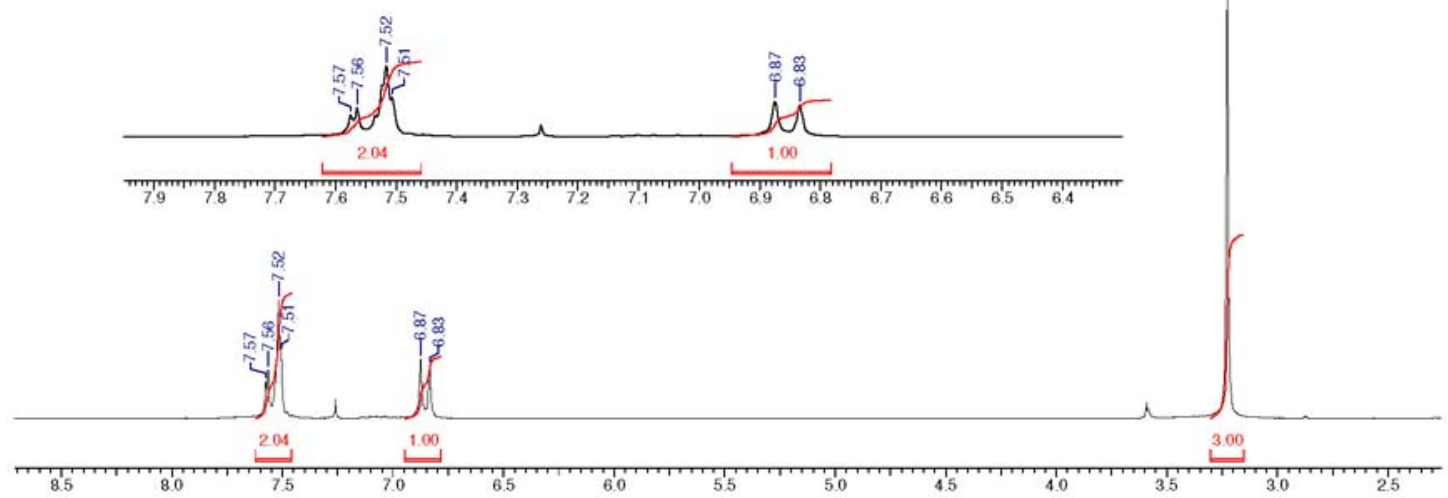

Figure S1. ${ }^{1} \mathrm{H}$ NMR of 1a. 


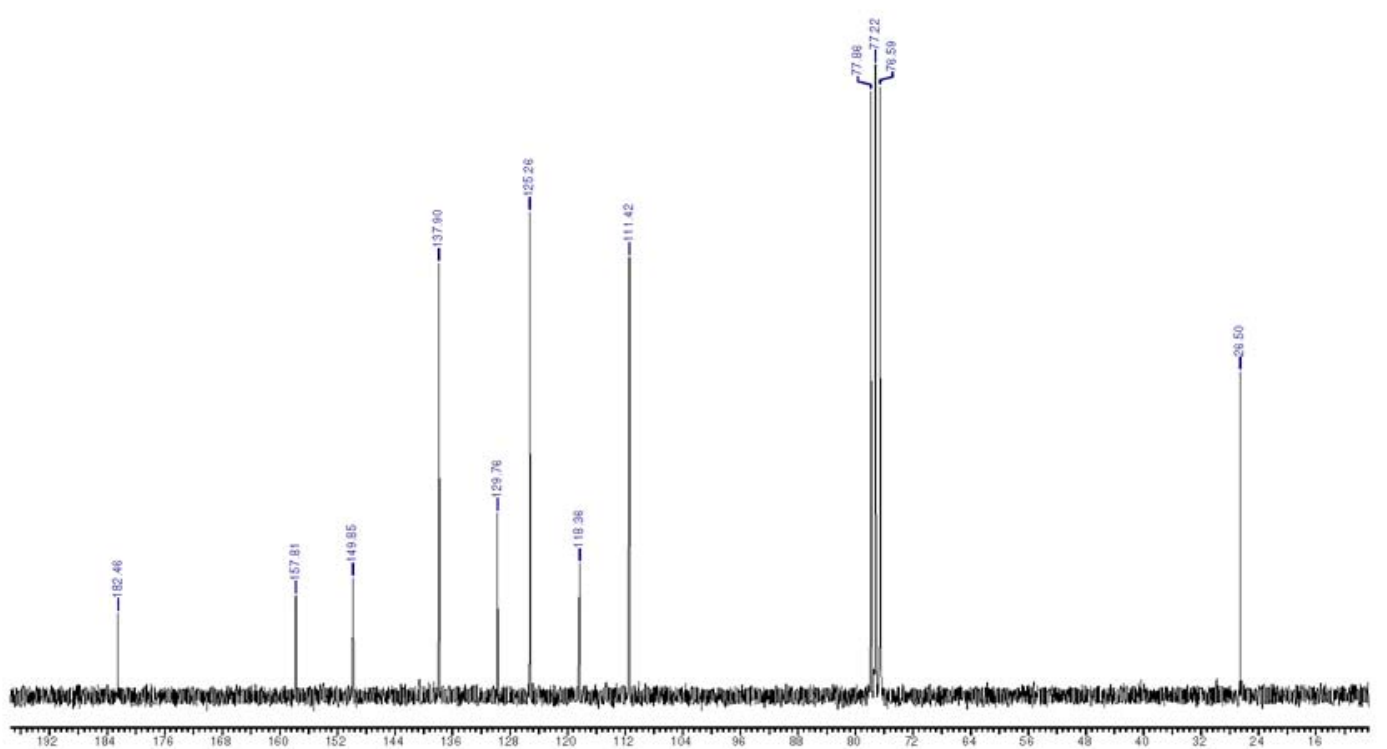

Figure S2. ${ }^{13} \mathrm{C}$ NMR of 1a.

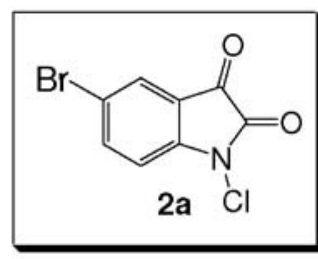

$2 a$
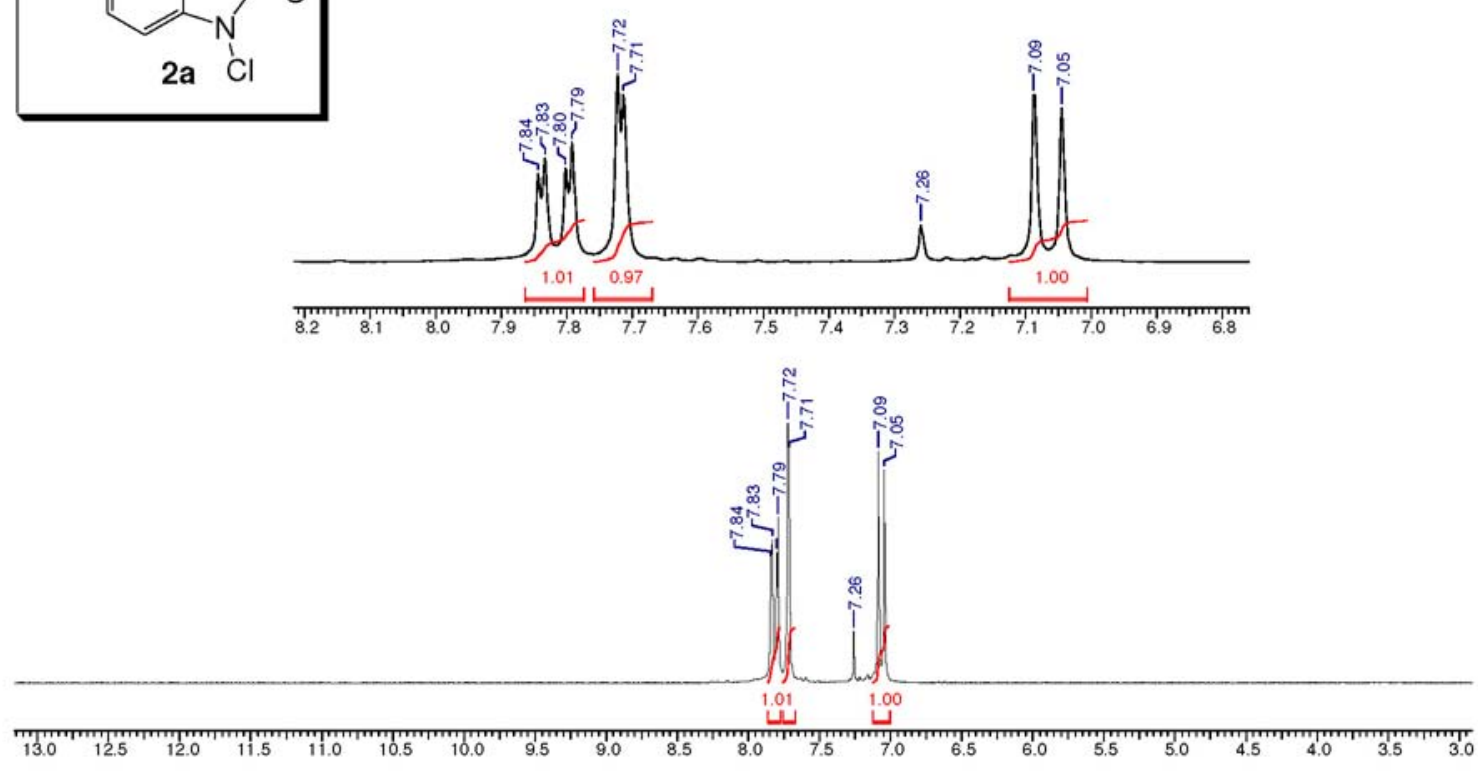

Figure S3. 'H NMR of 2a. 


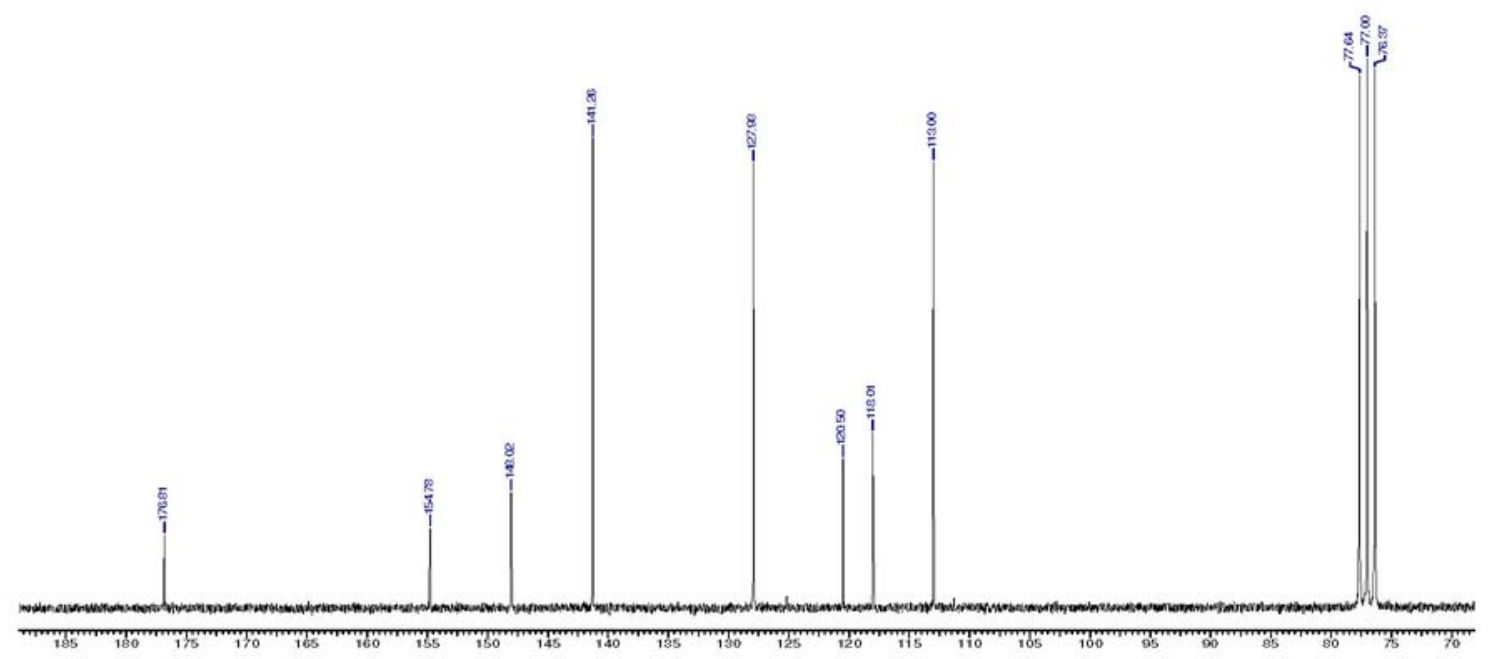

Figure S4. ${ }^{13} \mathrm{C}$ NMR of $\mathbf{2 a}$.

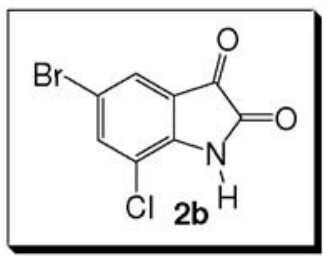

$2 \mathrm{~b}$
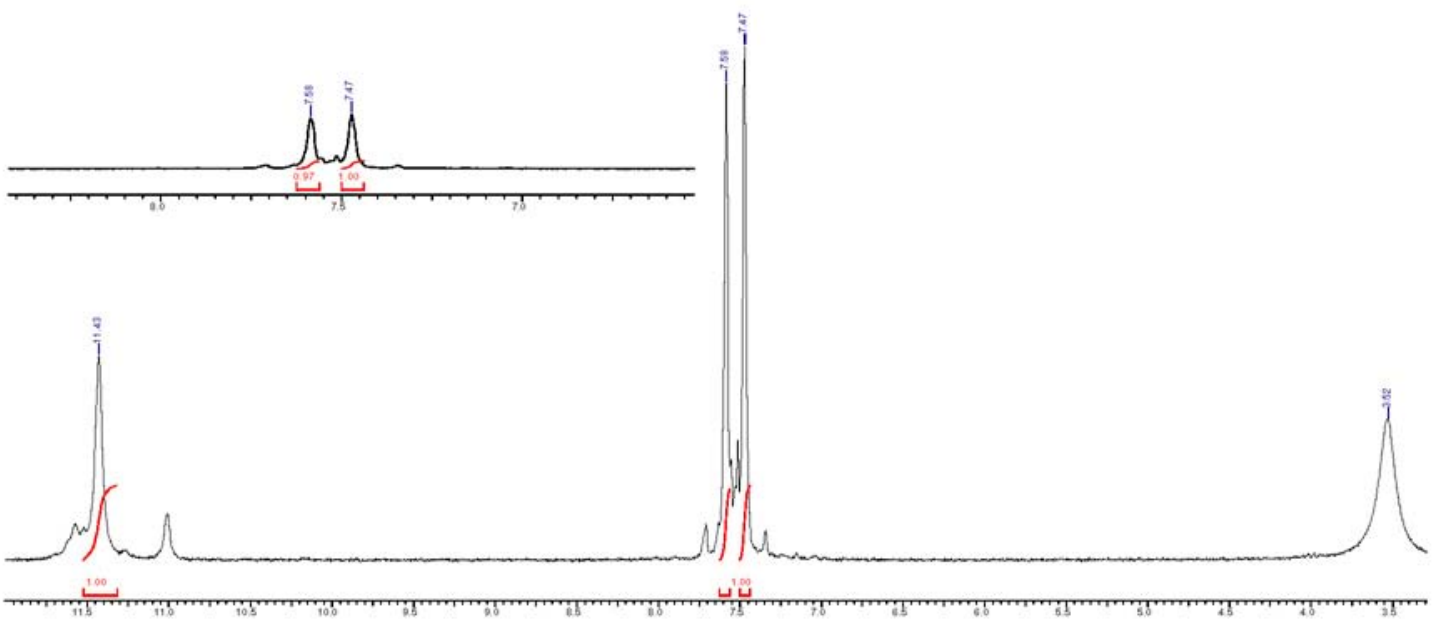

Figure S5. ${ }^{1} \mathrm{H}$ NMR of $\mathbf{2 b}$. 
$2 b$

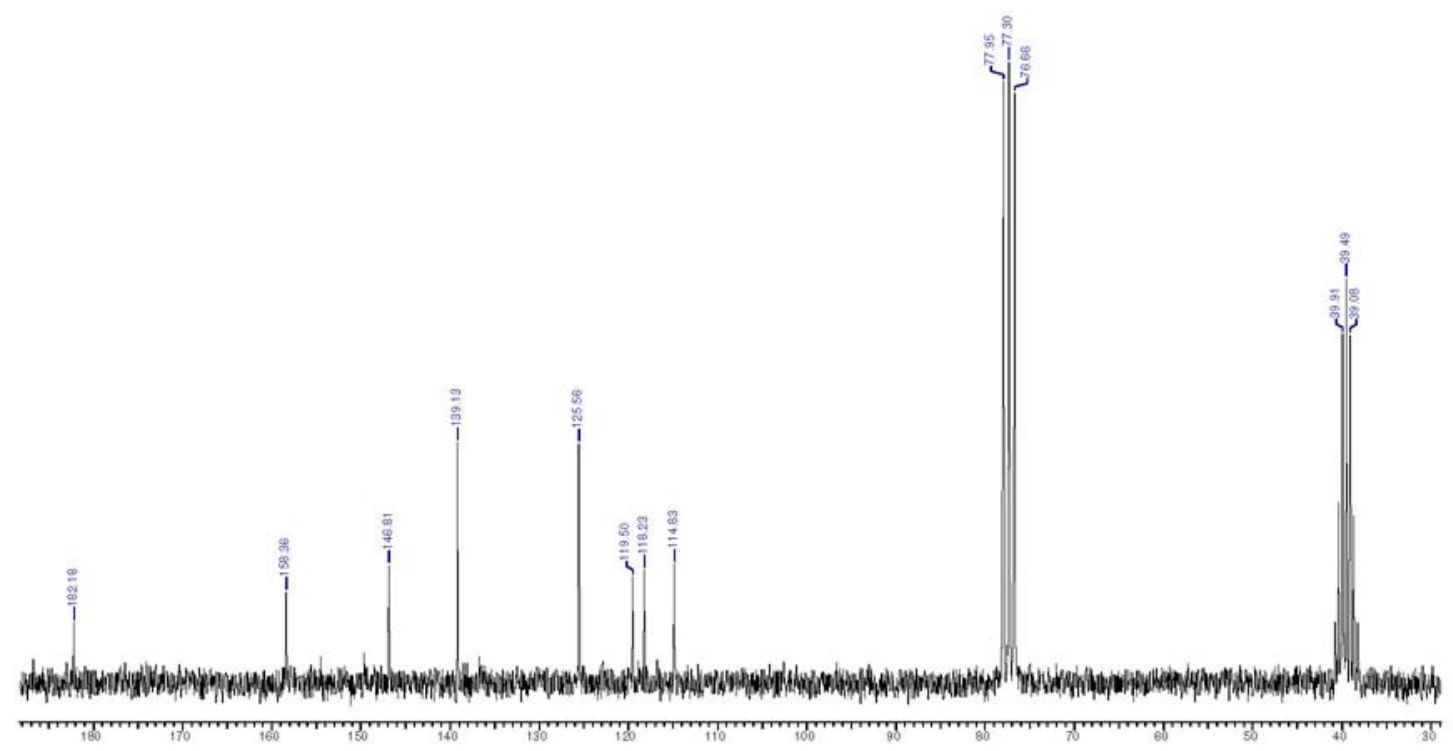

Figure S6. ${ }^{13} \mathrm{C}$ NMR of $\mathbf{2 b}$.

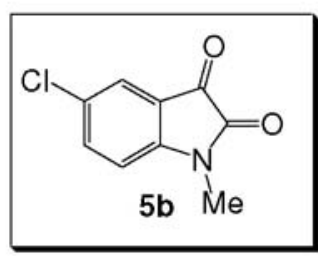

$5 b$

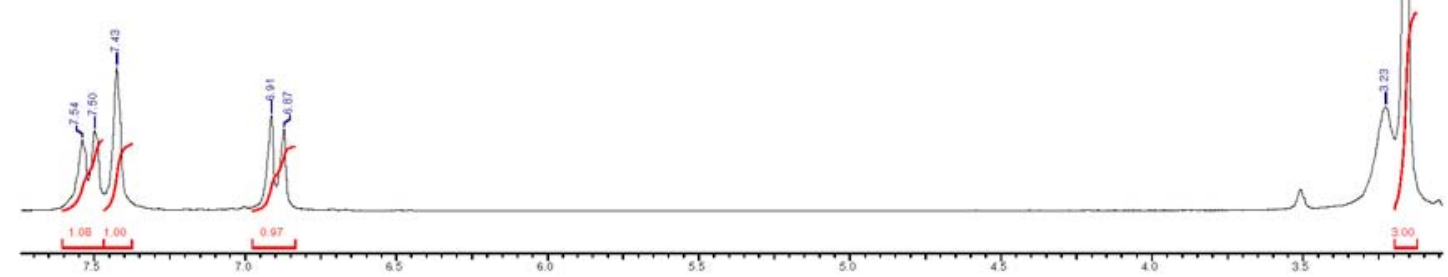

Figure S7. ${ }^{1} \mathrm{H}$ NMR of $\mathbf{5 b}$. 
$5 b$

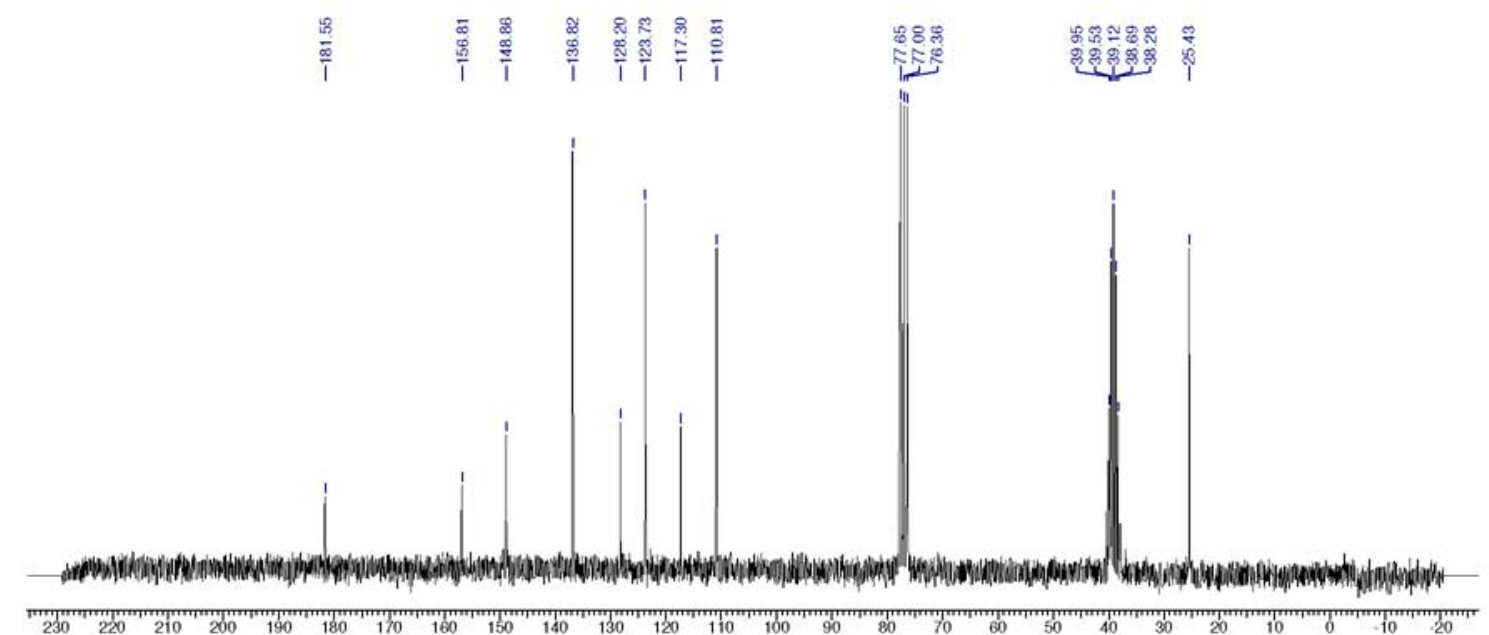

Figure S8. ${ }^{13} \mathrm{C}$ NMR of $\mathbf{5 b}$.

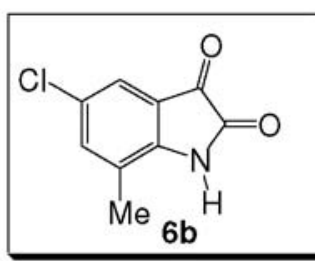

$6 b$

సิ
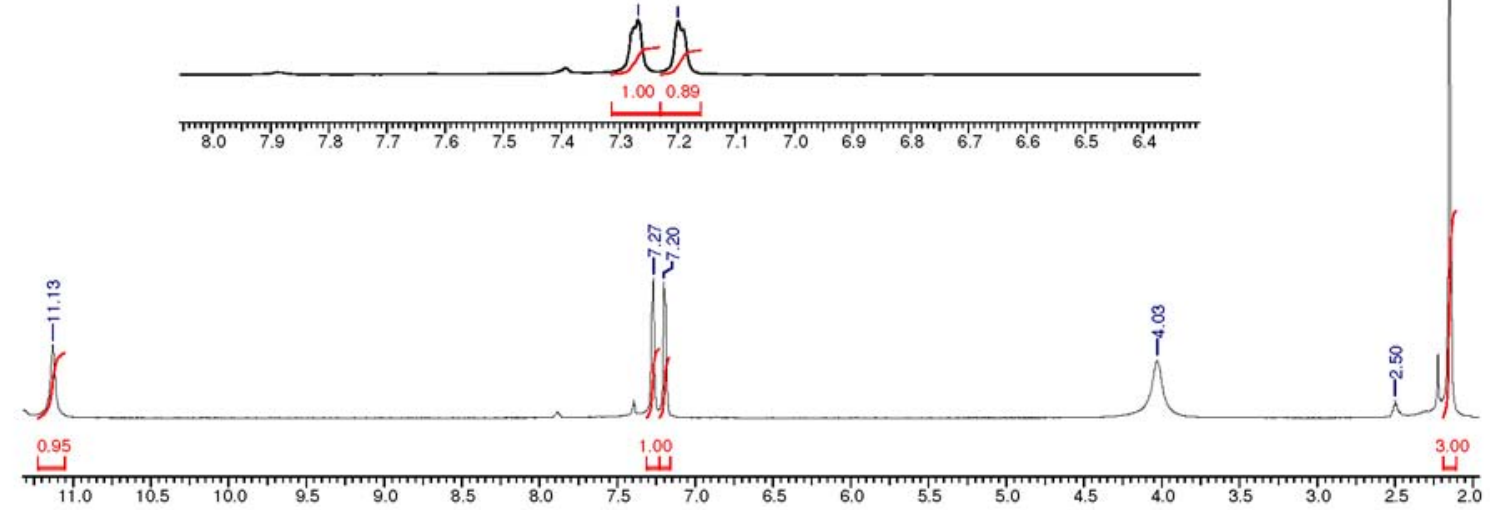

Figure S9. ${ }^{1} \mathrm{H}$ NMR of $\mathbf{6 b}$. 
$6 b$

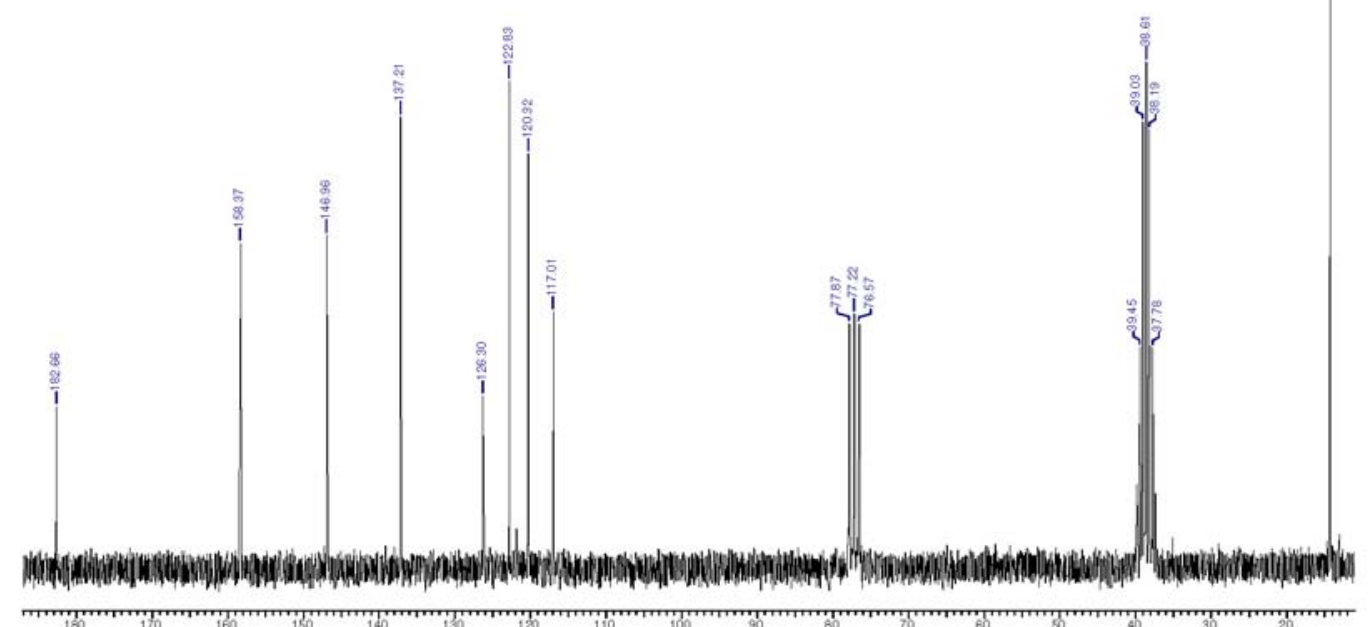

Figure S10. ${ }^{13} \mathrm{C}$ NMR of $\mathbf{6 b}$.<smiles>O=C1Nc2c(Cl)cc(F)cc2C1=O</smiles>

$7 b$
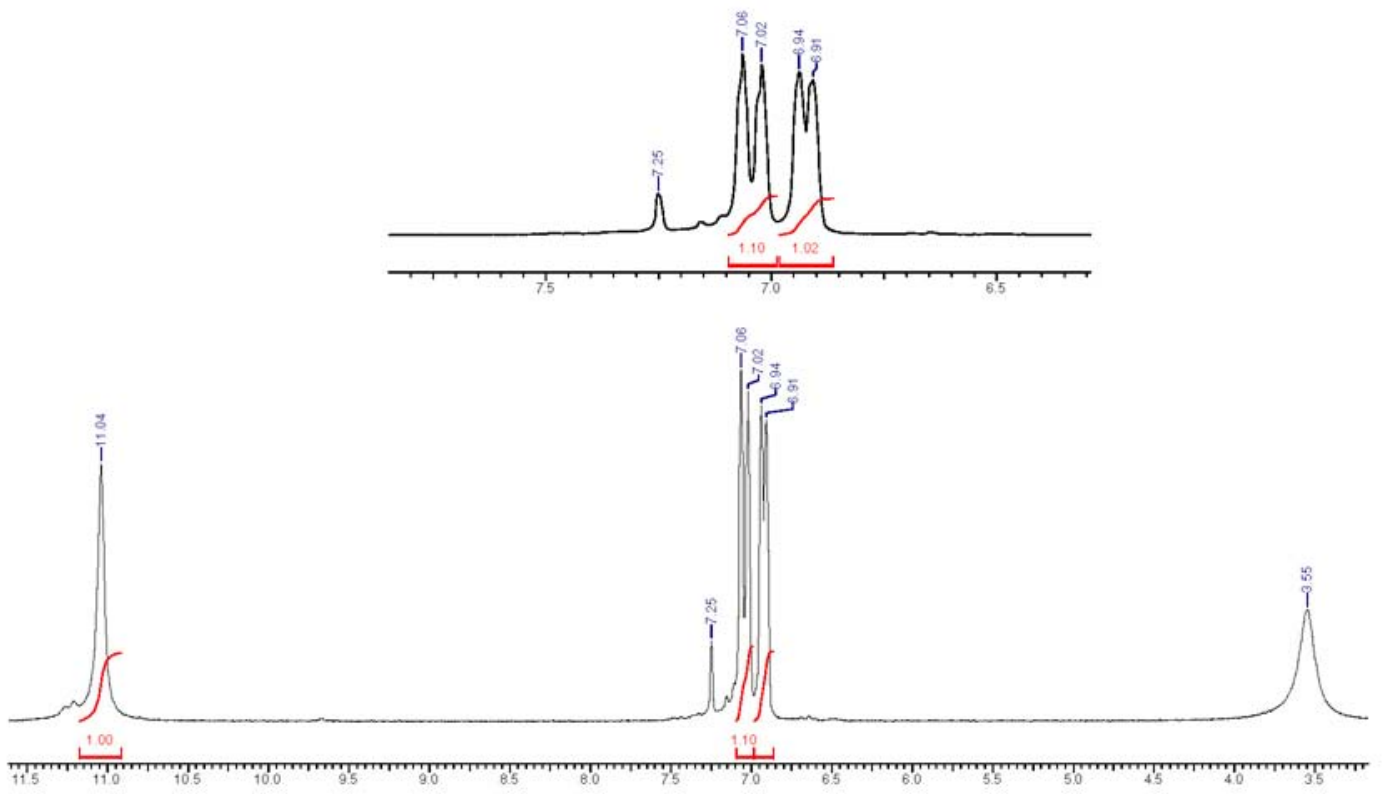

Figure S11. ${ }^{1} \mathrm{H}$ NMR of $7 \mathbf{b}$. 


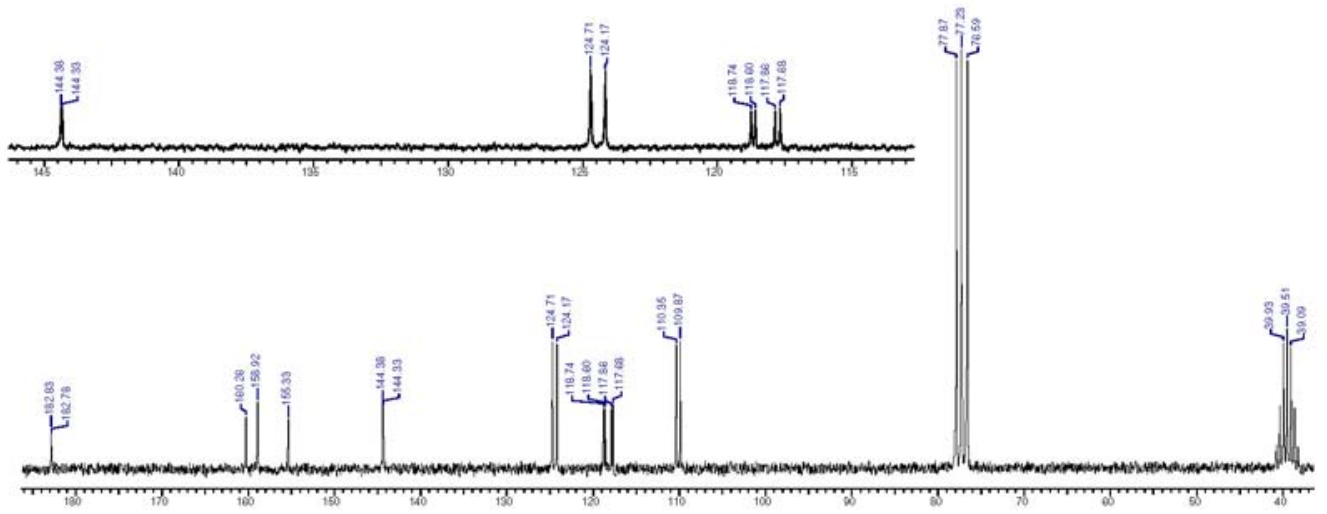

Figure S12. ${ }^{13} \mathrm{C}$ NMR of $7 \mathbf{b}$.

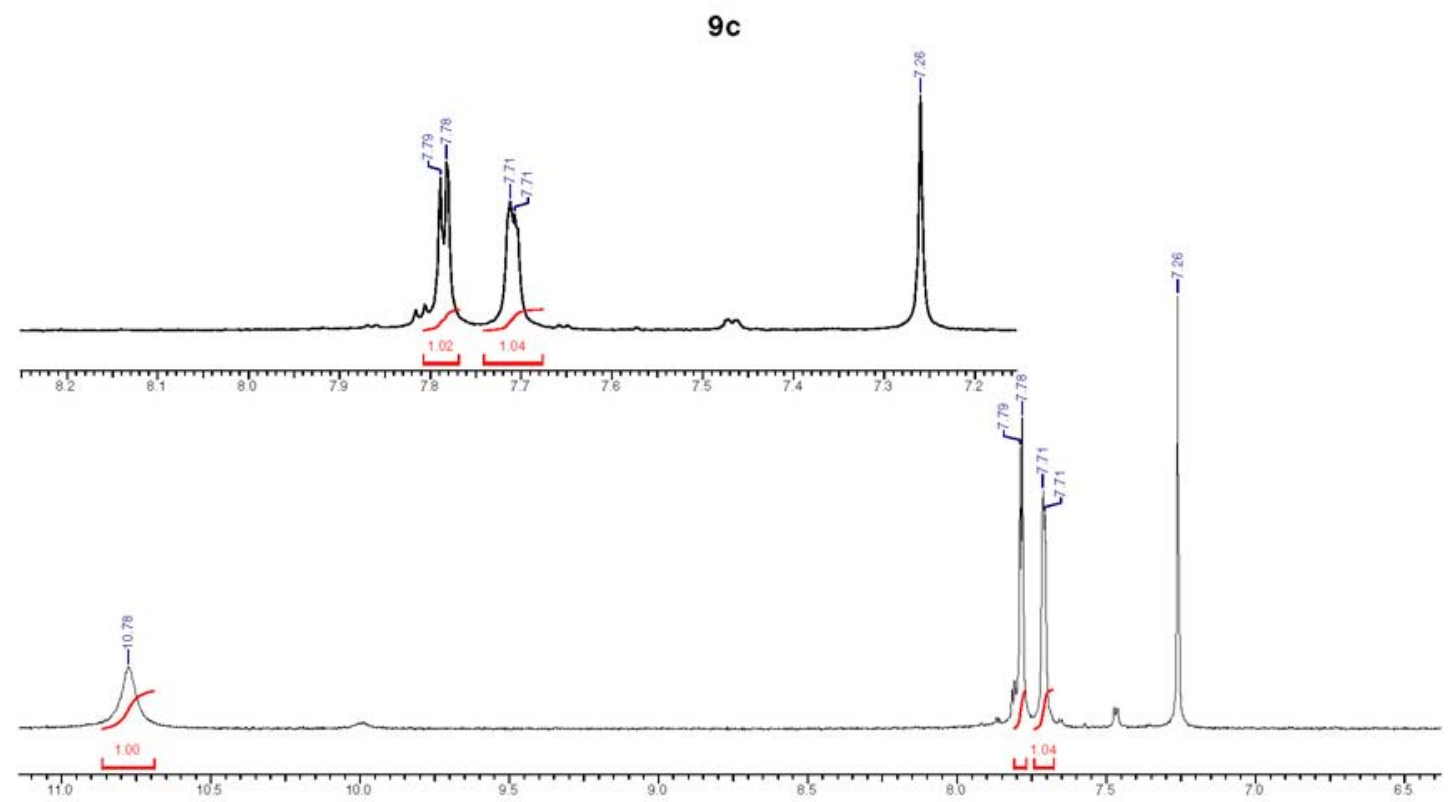

Figure S13. ${ }^{1} \mathrm{H}$ NMR of $9 c$. 


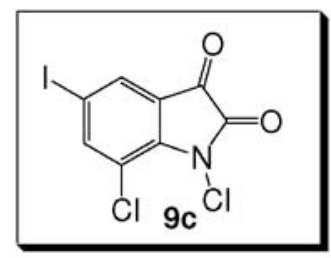

$9 c$

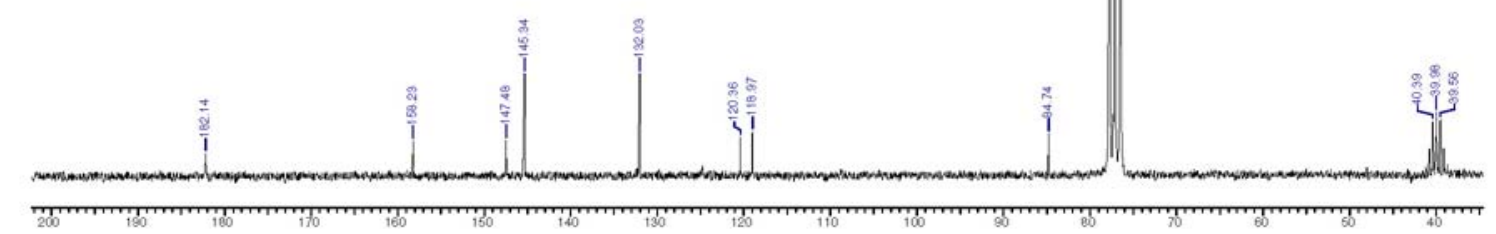

Figure S14. ${ }^{13} \mathrm{C}$ NMR of 9 c.
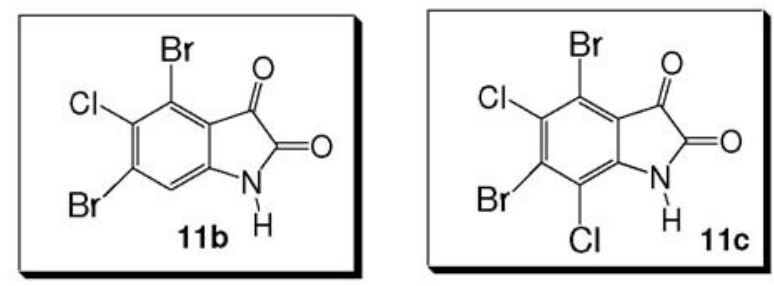

11b (mixture with 11c)

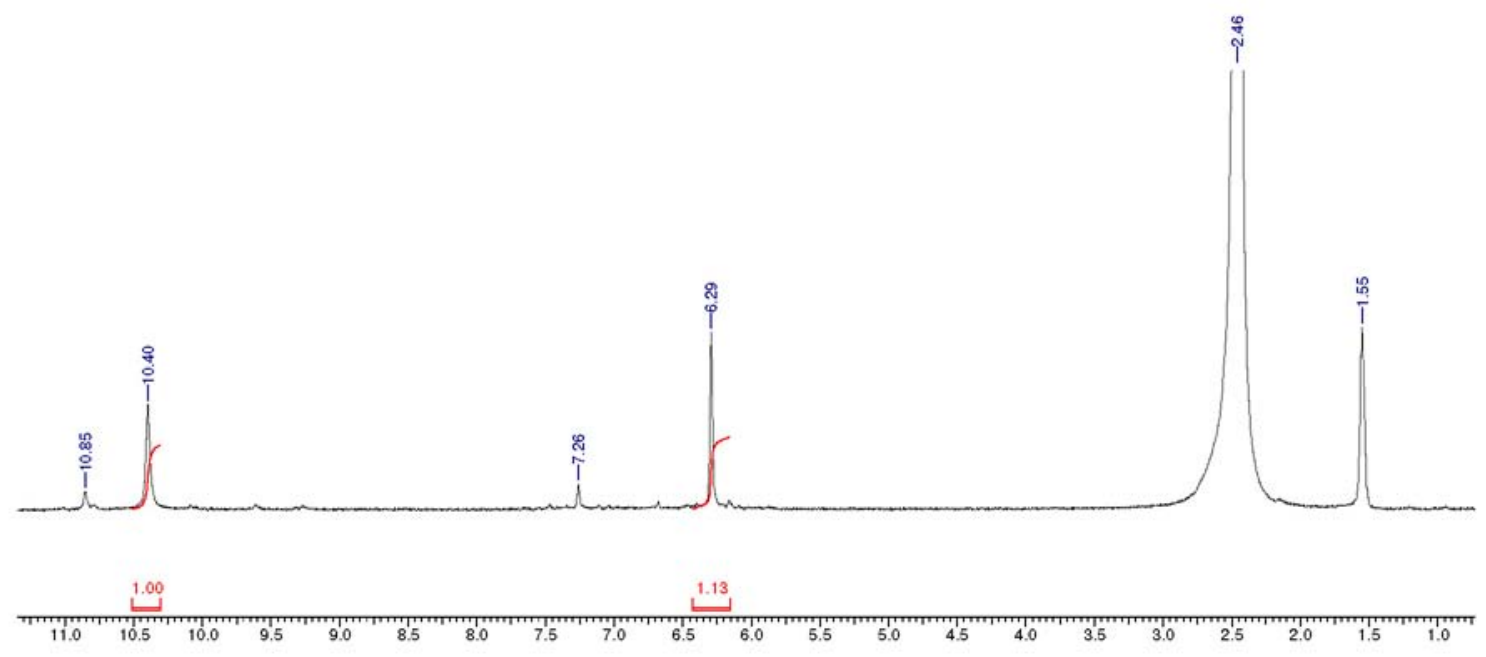

Figure S15. ${ }^{1} \mathrm{H}$ NMR of $\mathbf{1 1 b}$ (mixture with 11c). 


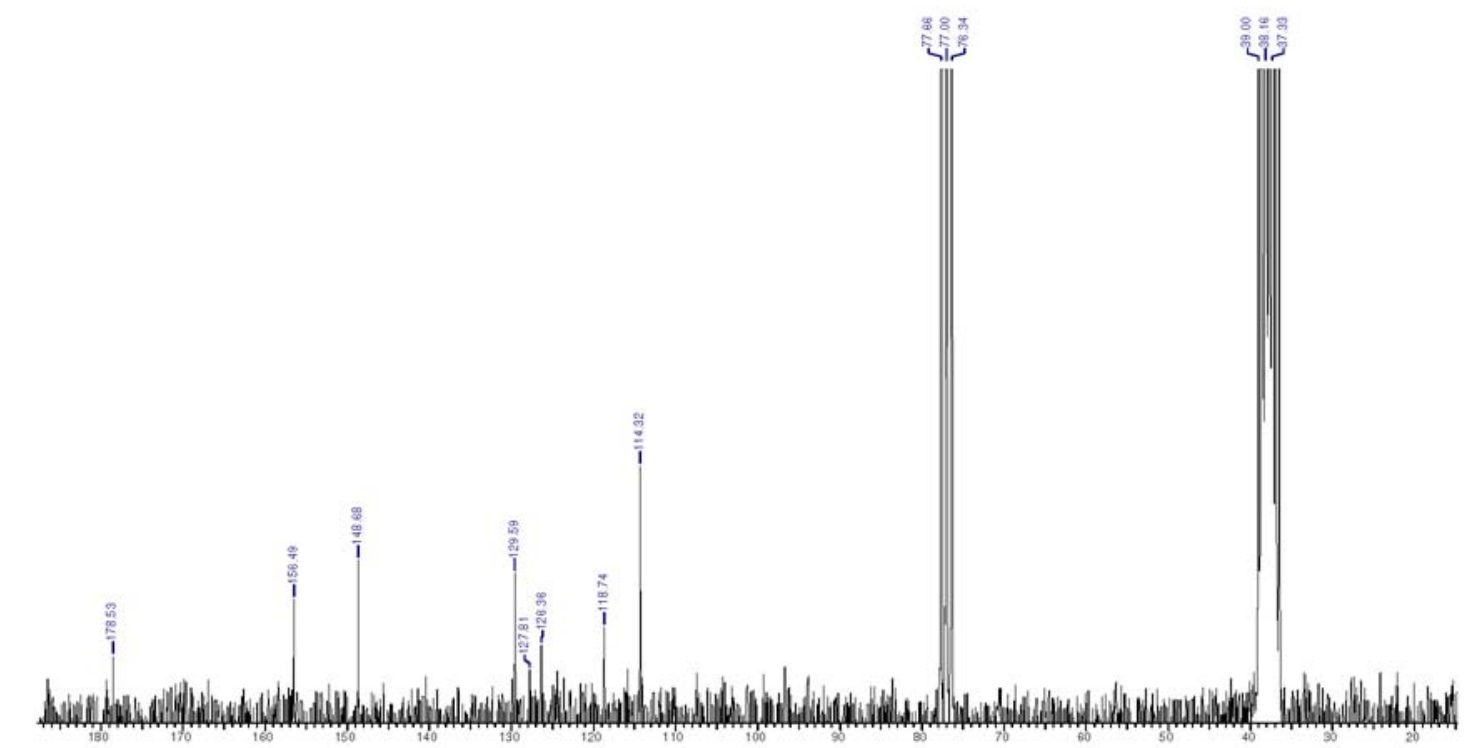

Figure S16. ${ }^{13} \mathrm{C}$ NMR of $\mathbf{1 1 b}$.

\section{FTIR spectra}

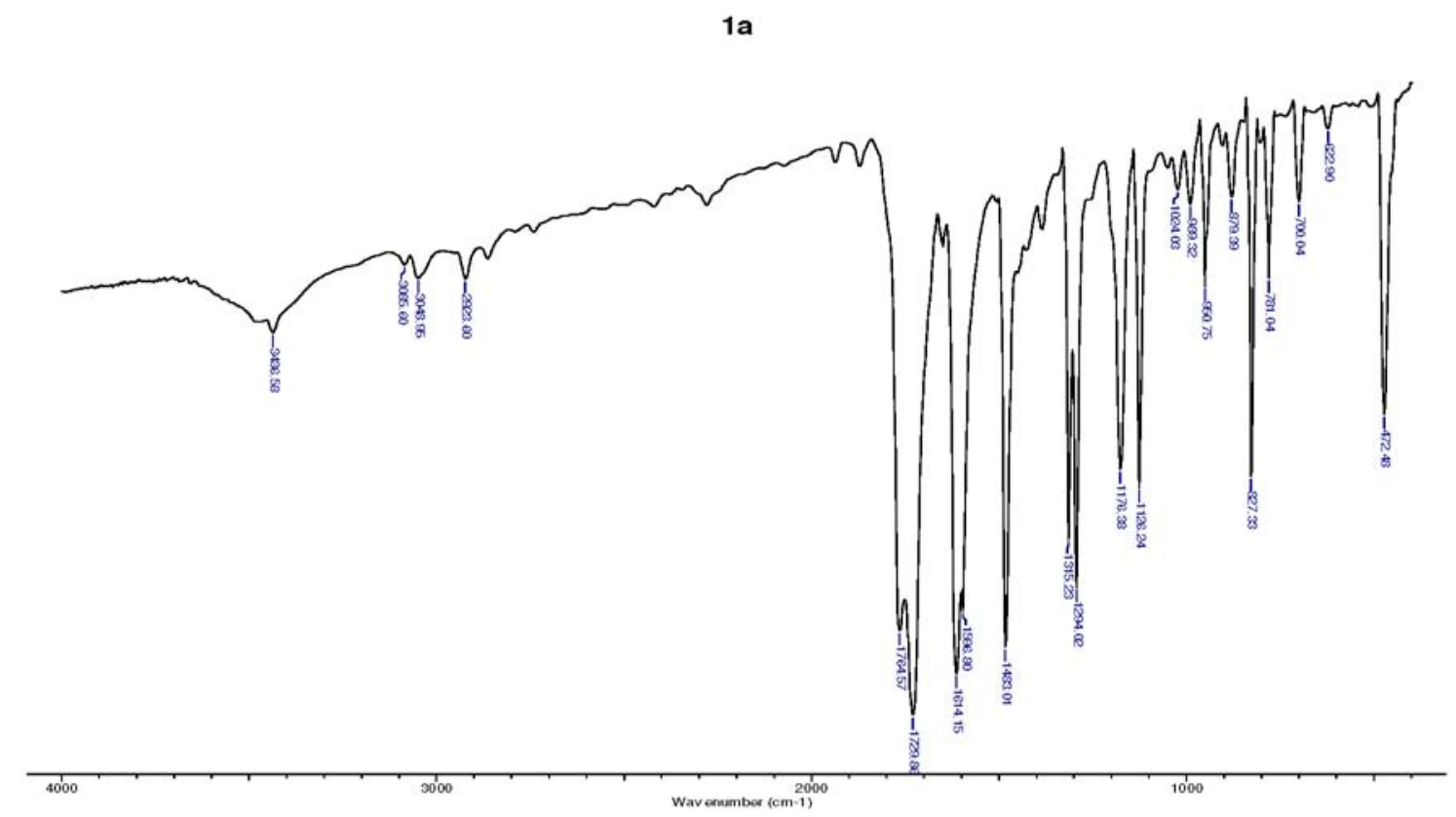

Figure S17. FTIR spectra of 1a. 


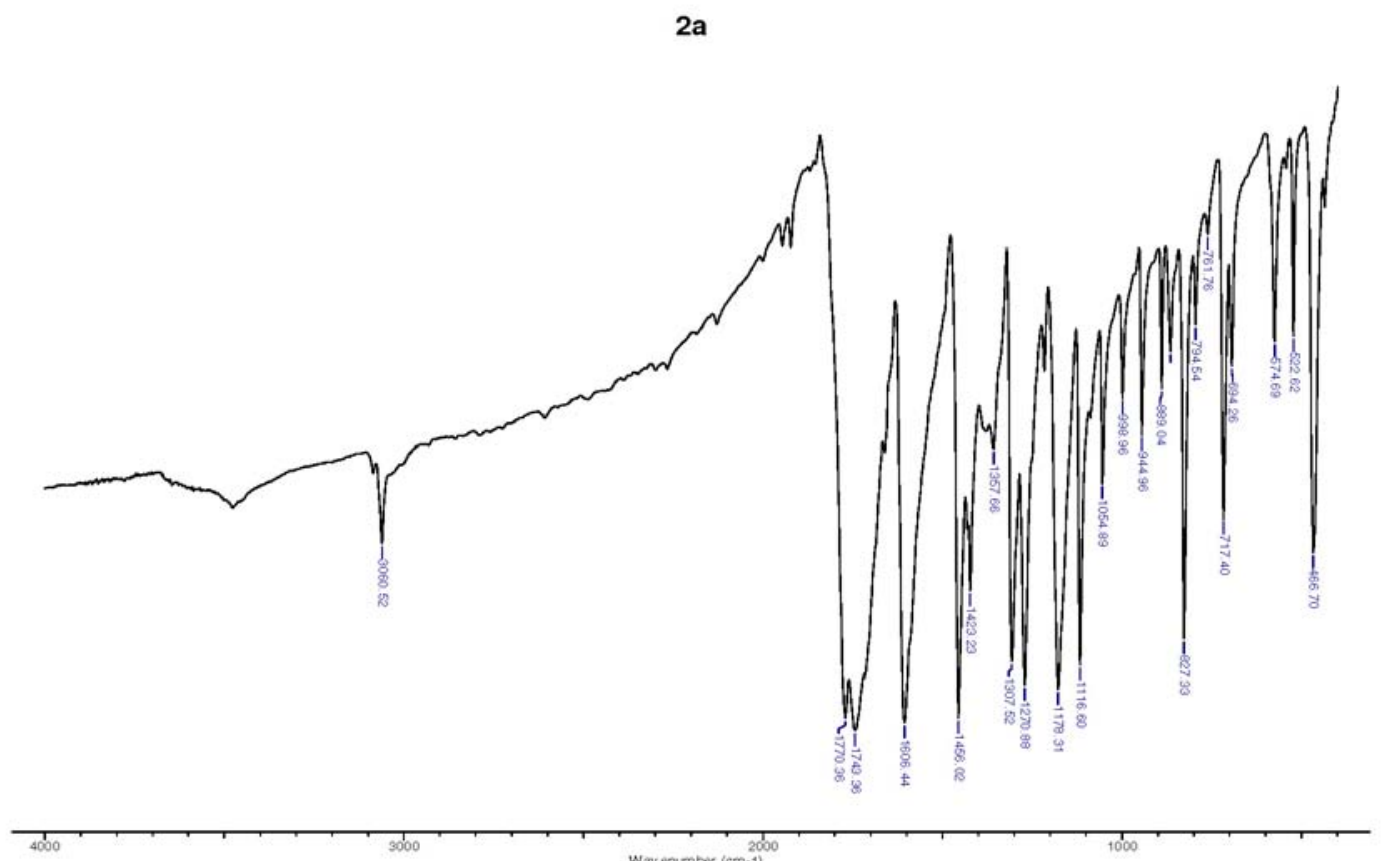

Figure S18. FTIR spectra of 2a.

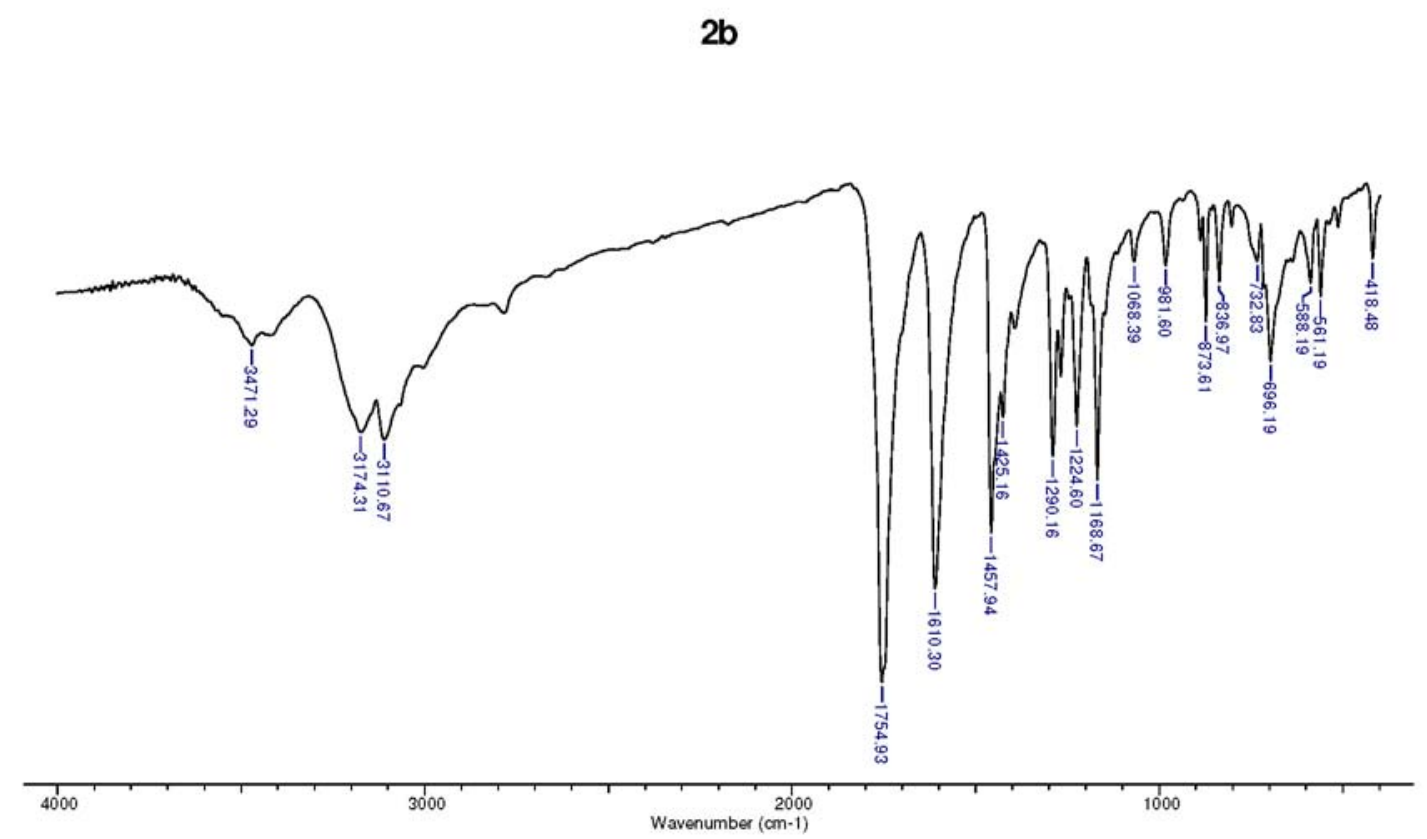

Figure S19. FTIR spectra of $2 \mathbf{b}$. 
$5 b$
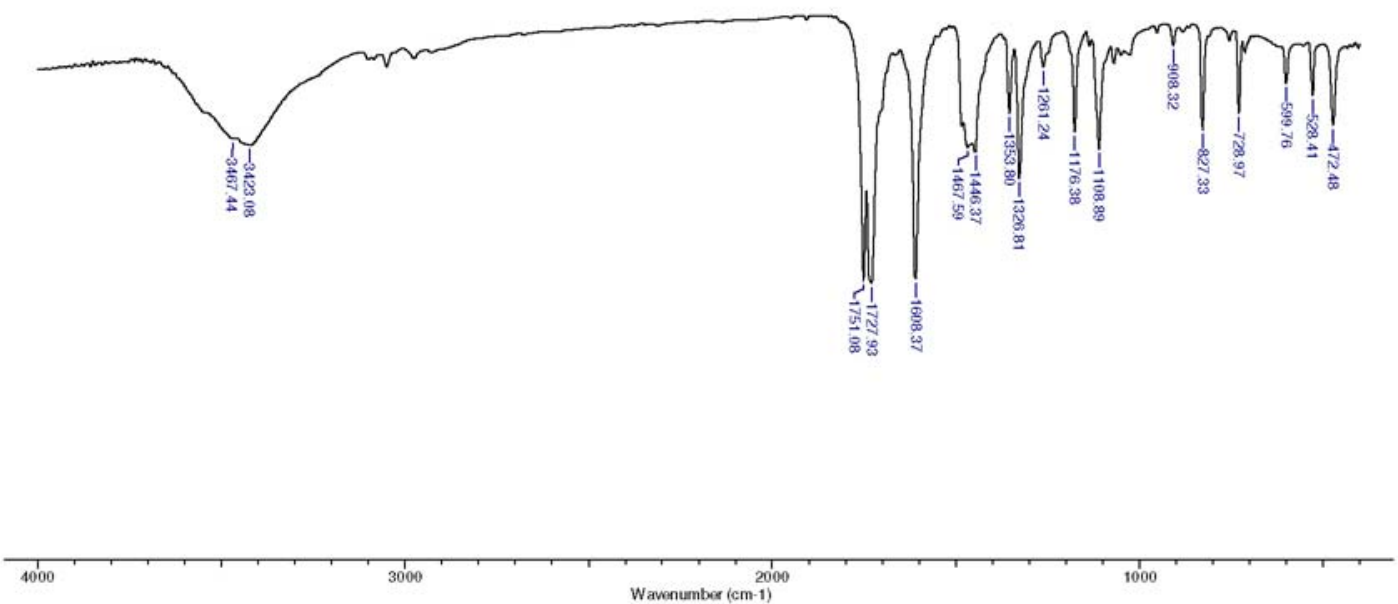

Figure S20. FTIR spectra of $\mathbf{5 b}$.

$6 b$

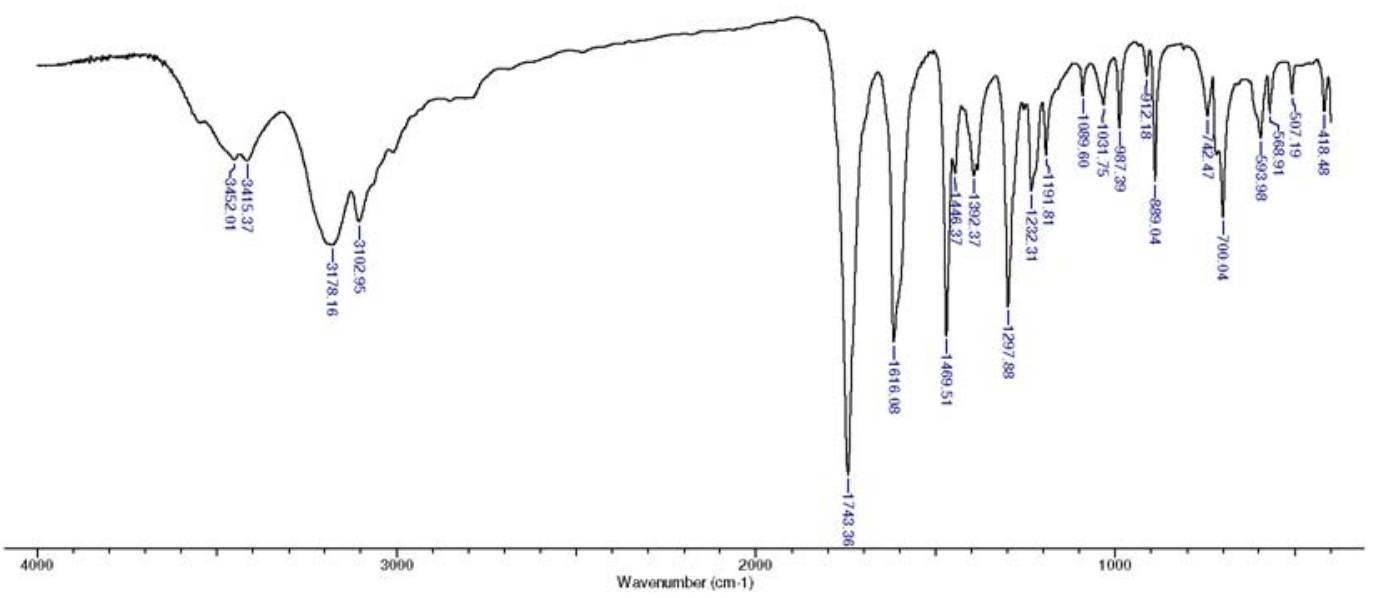

Figure S21. FTIR spectra of $\mathbf{6 b}$. 
$7 b$

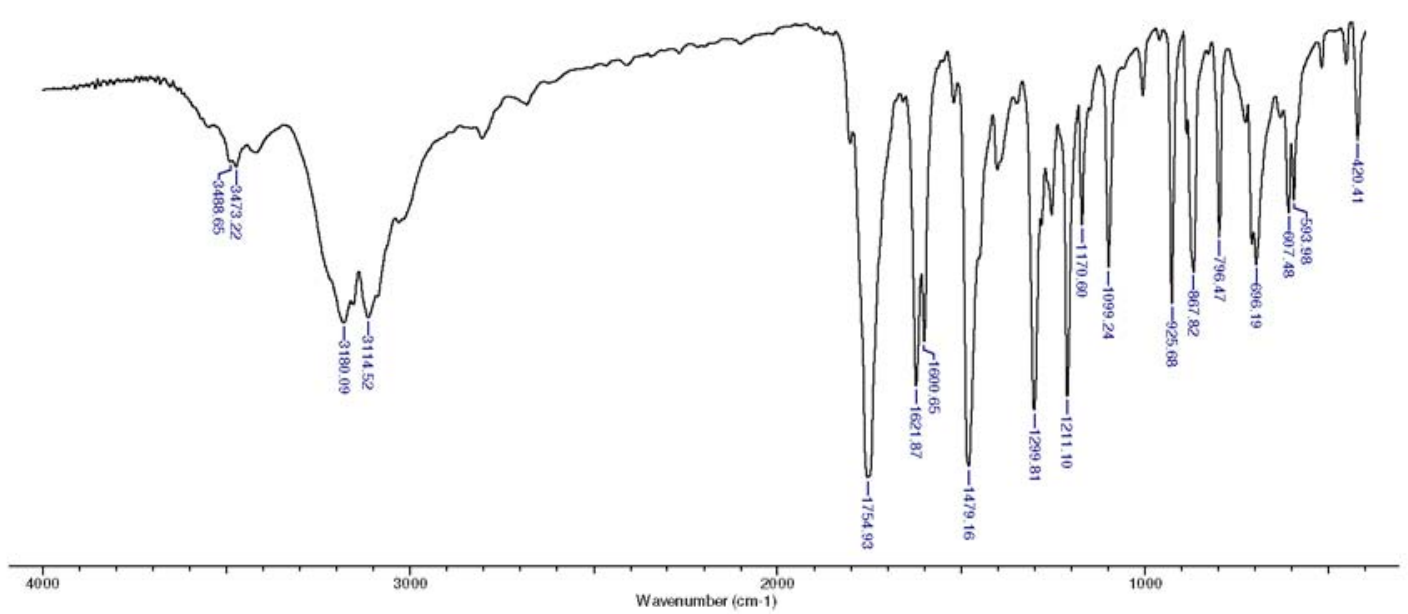

Figure S22. FTIR spectra of 7b.

9c
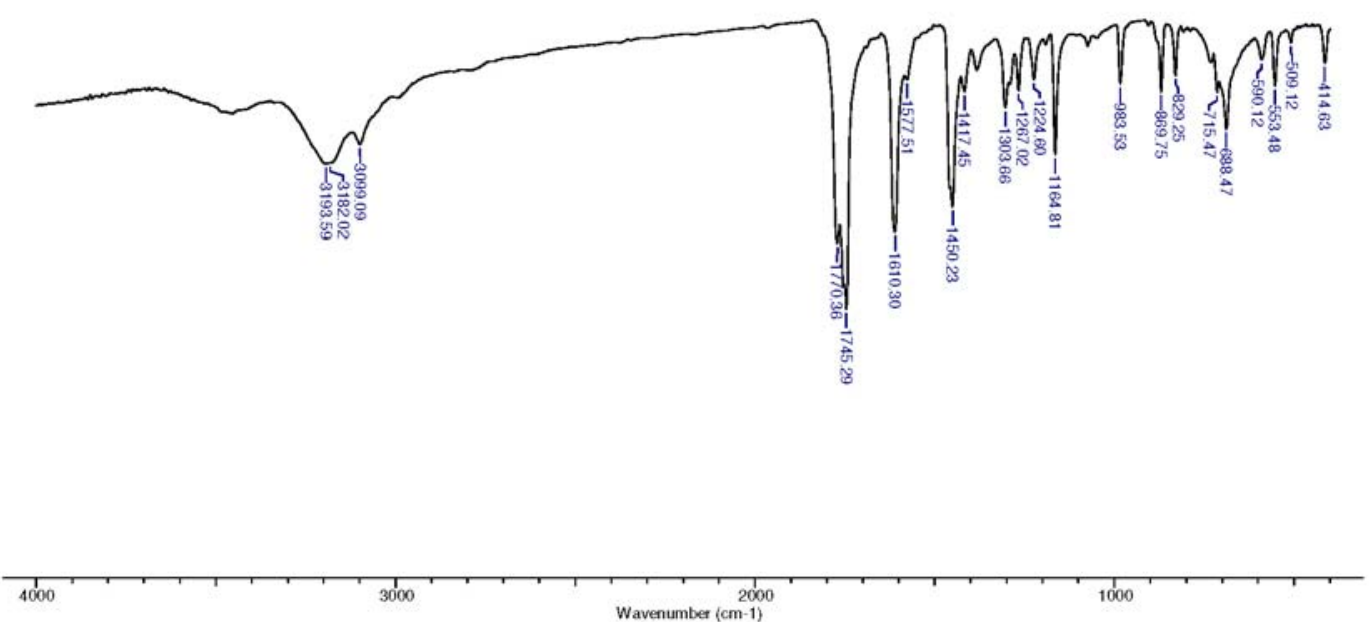

Figure S23. FTIR spectra of 9c. 
11b

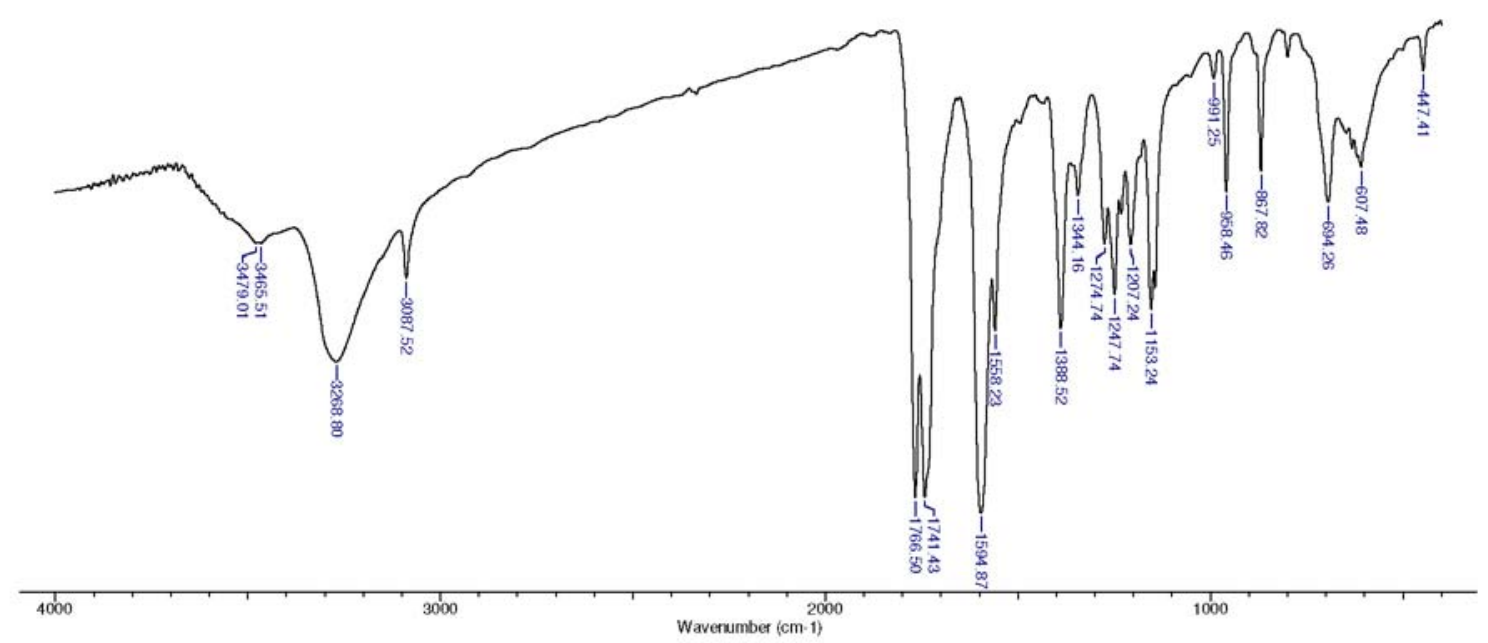

Figure S24. FTIR spectra of 11b.

\section{Mass Spectra}

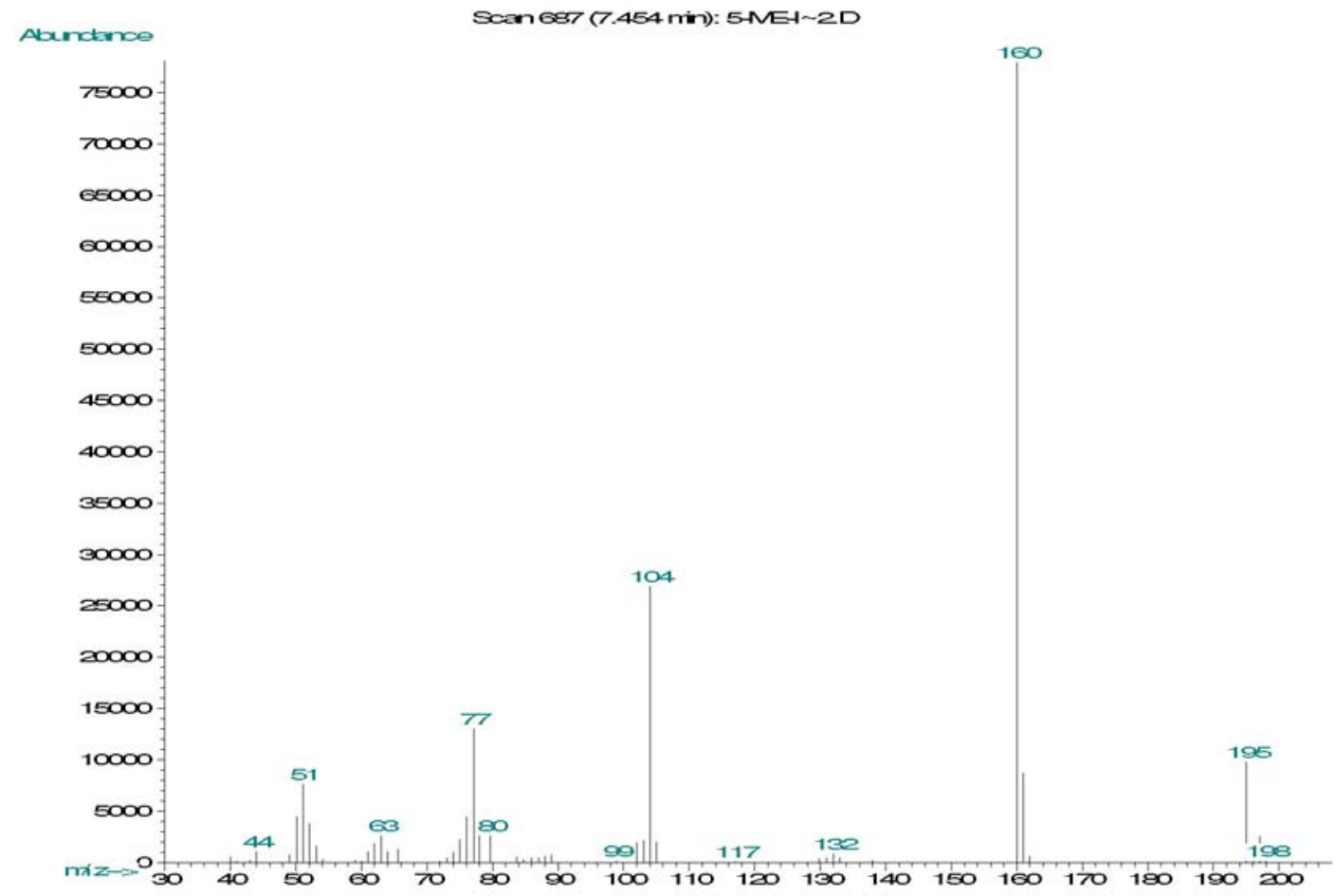

Figure S25. Mass spectrum of $\mathbf{1 a}$. 


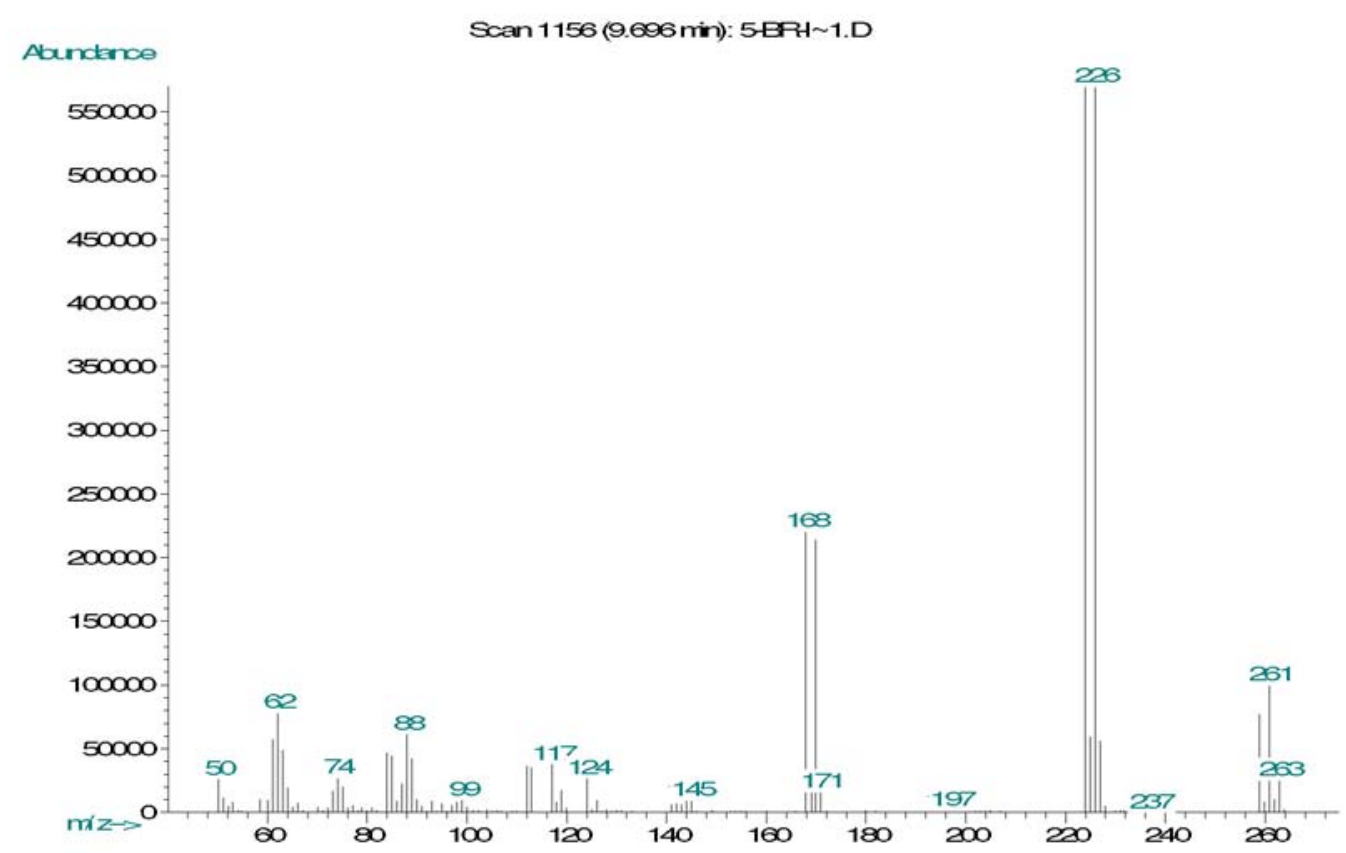

Figure S26. Mass spectrum of 2a.

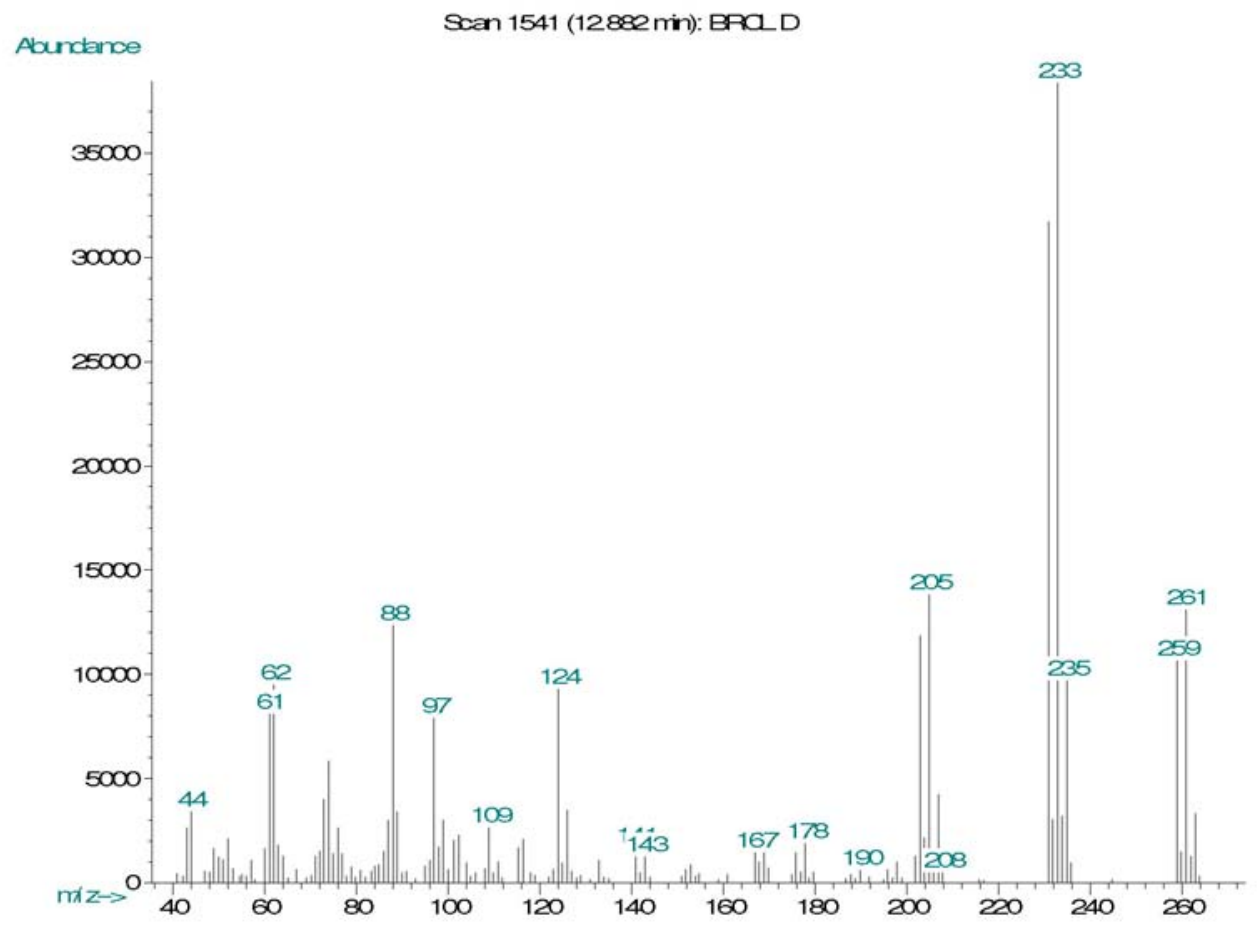

Figure S27. Mass spectrum of $\mathbf{2 b .}$ 


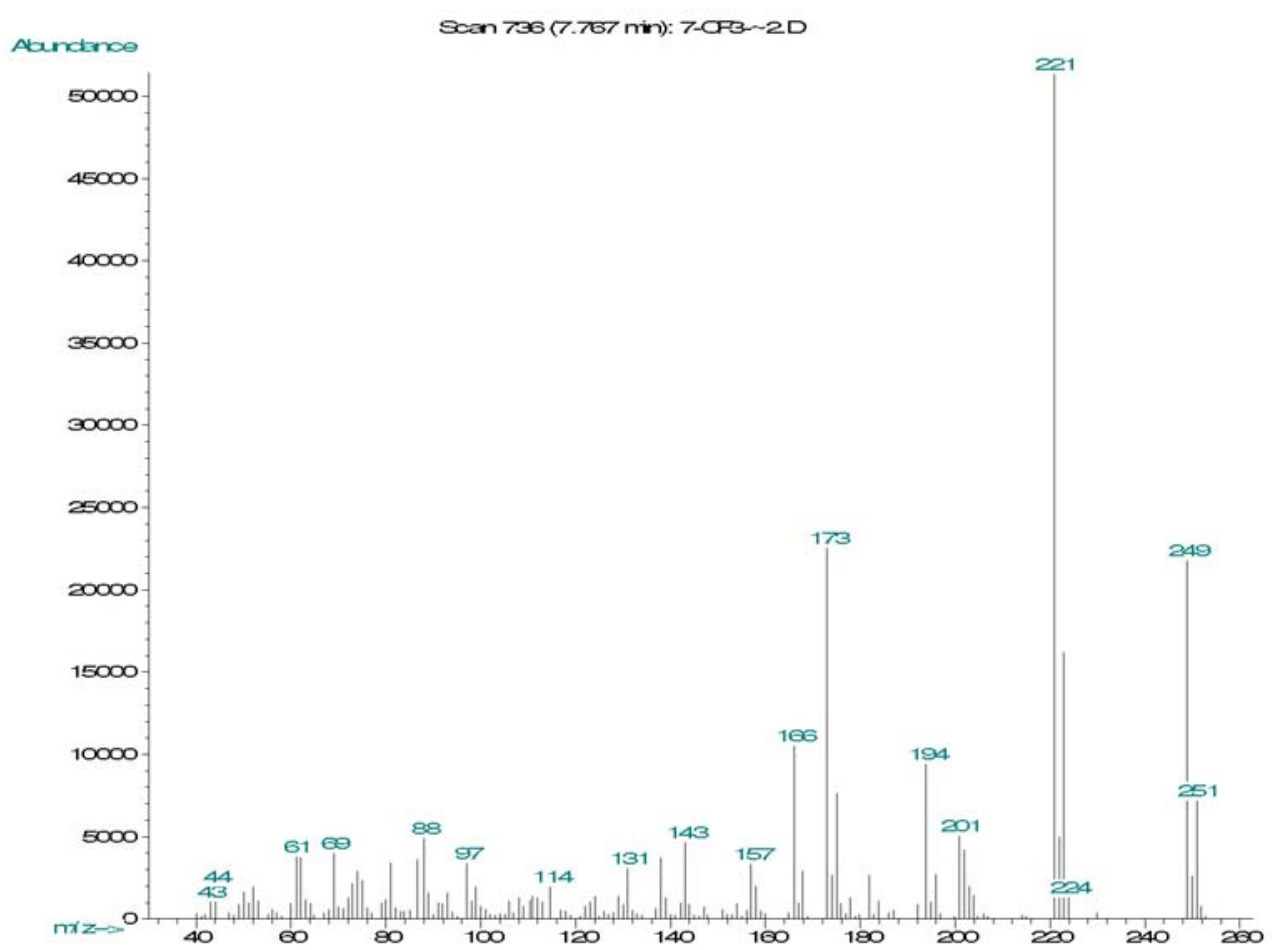

Figure S28. Mass spectrum of $\mathbf{4 b}$.

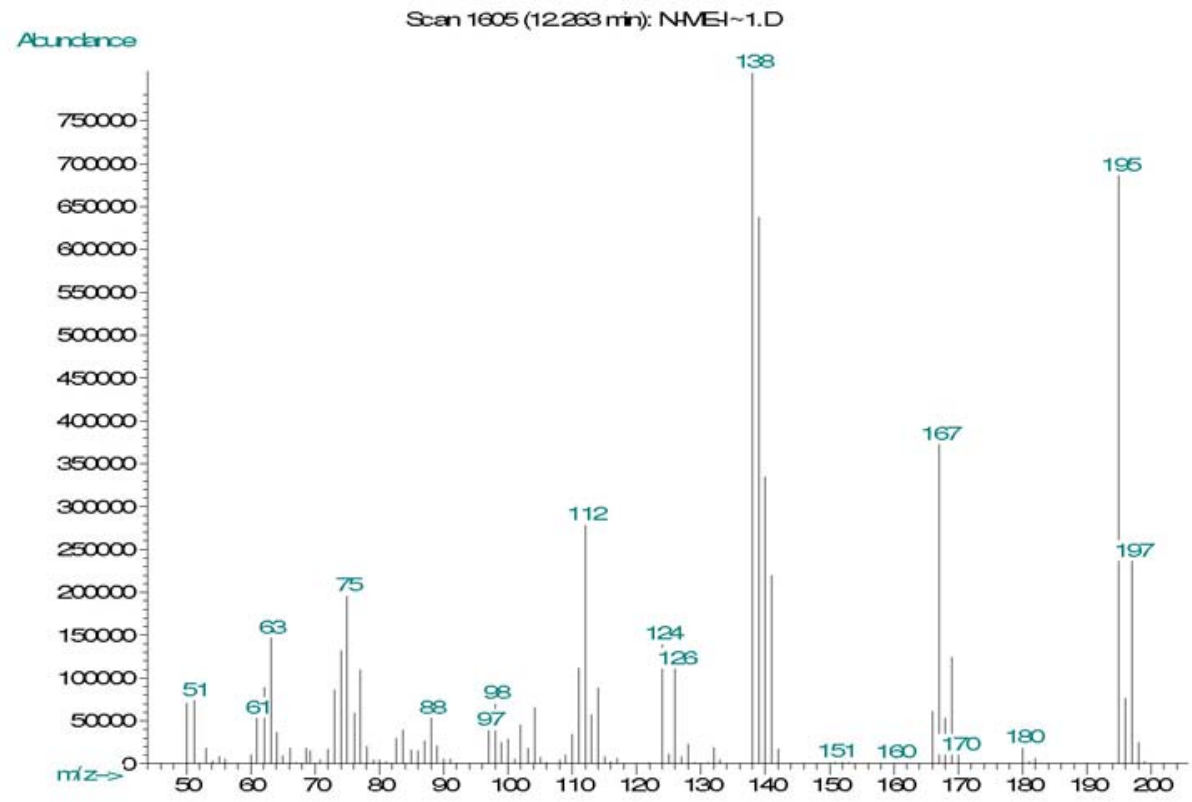

Figure S29. Mass spectrum of $\mathbf{5 b}$. 


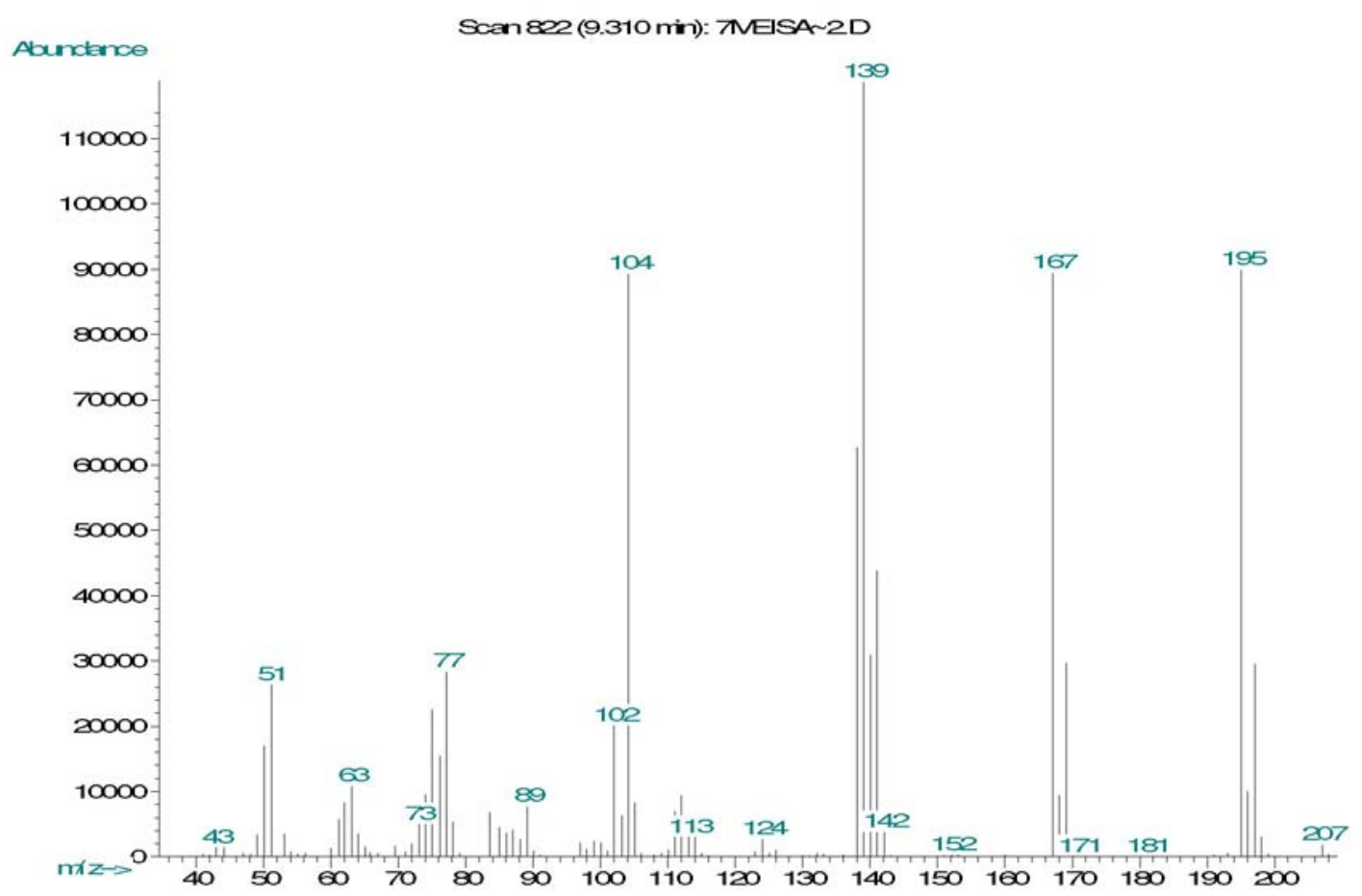

Figure S30. Mass spectrum of $6 \mathbf{b}$.

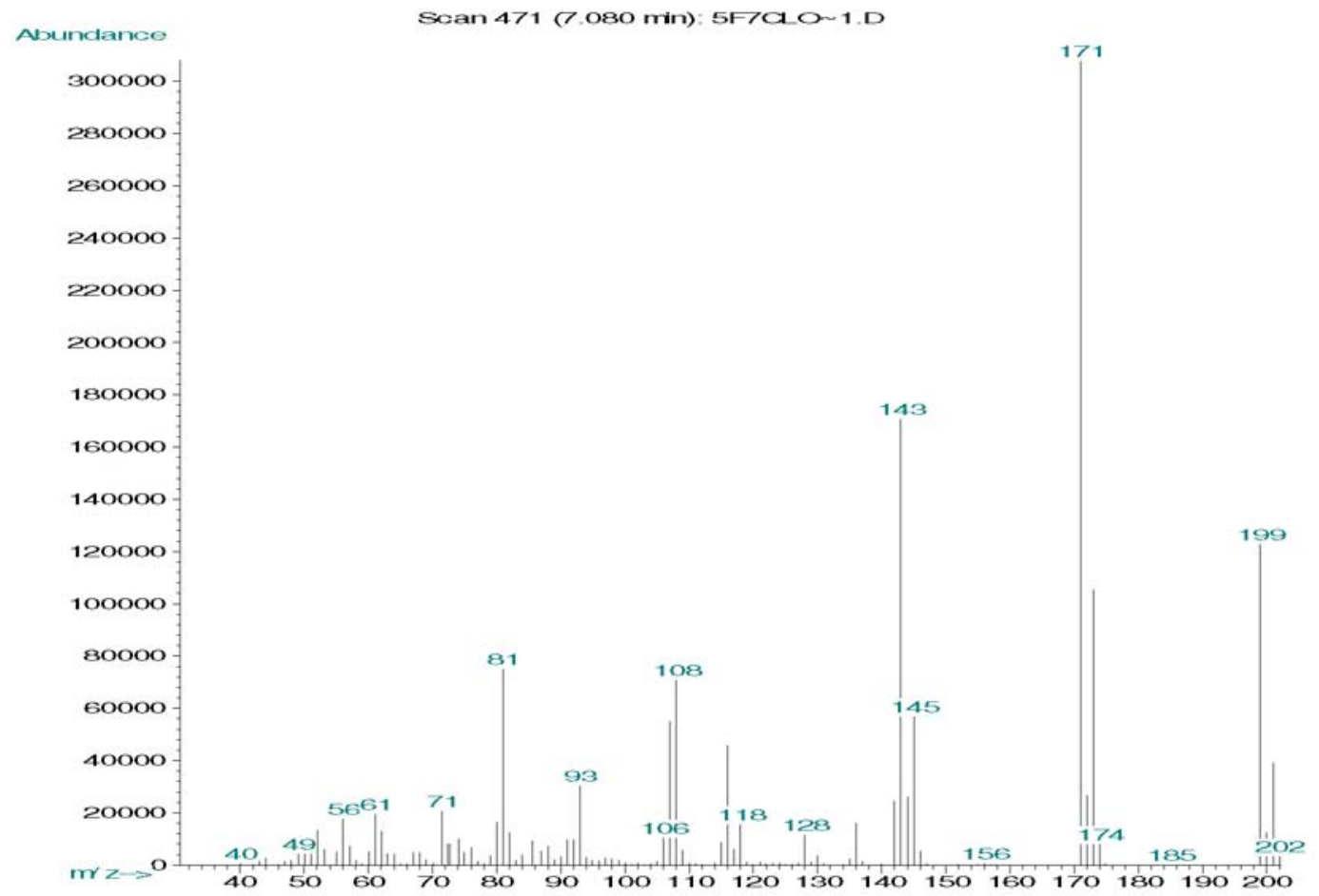

Figure S31. Mass spectrum of 7b. 


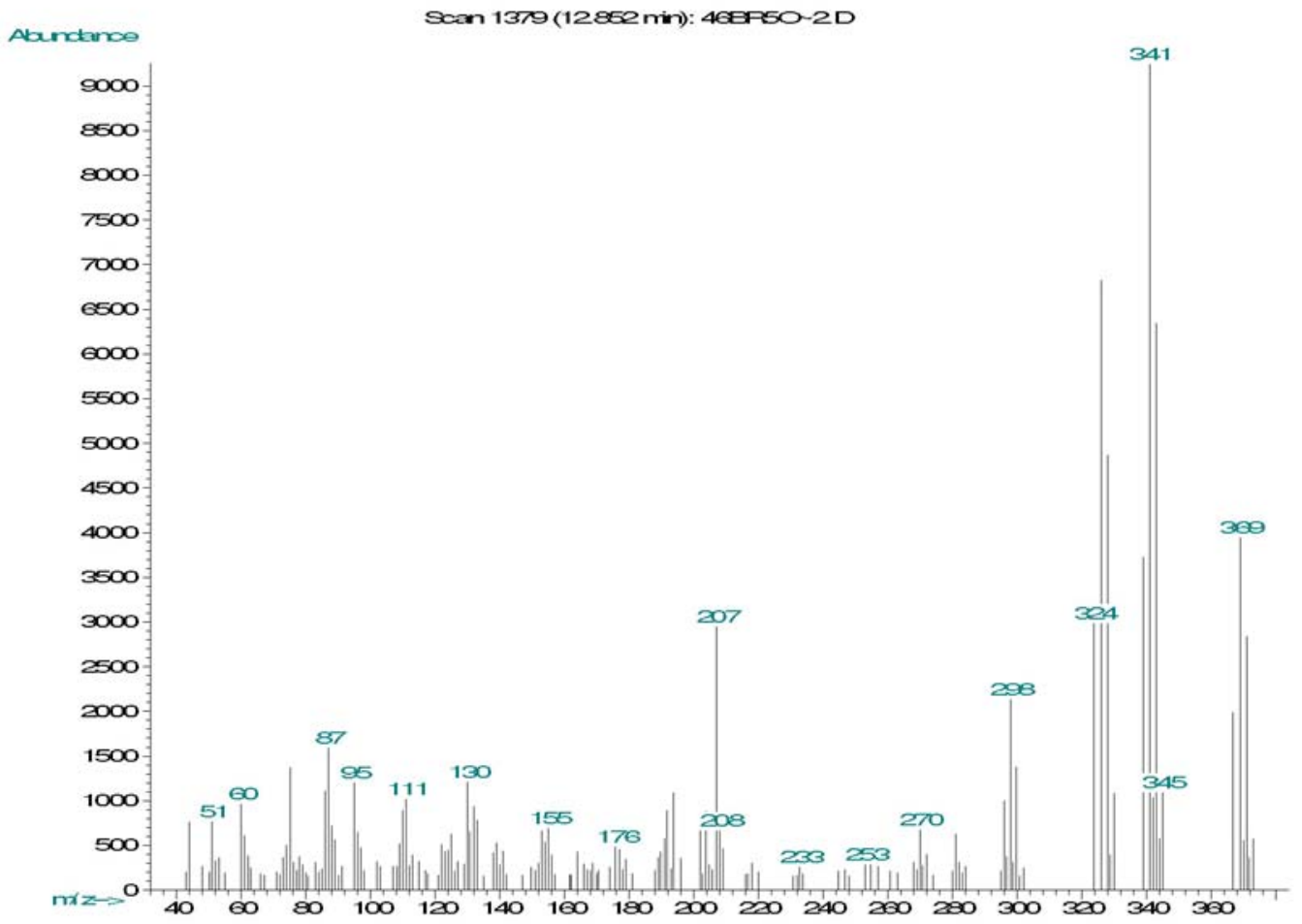

Figure S32. Mass spectrum of $\mathbf{8 b}$.

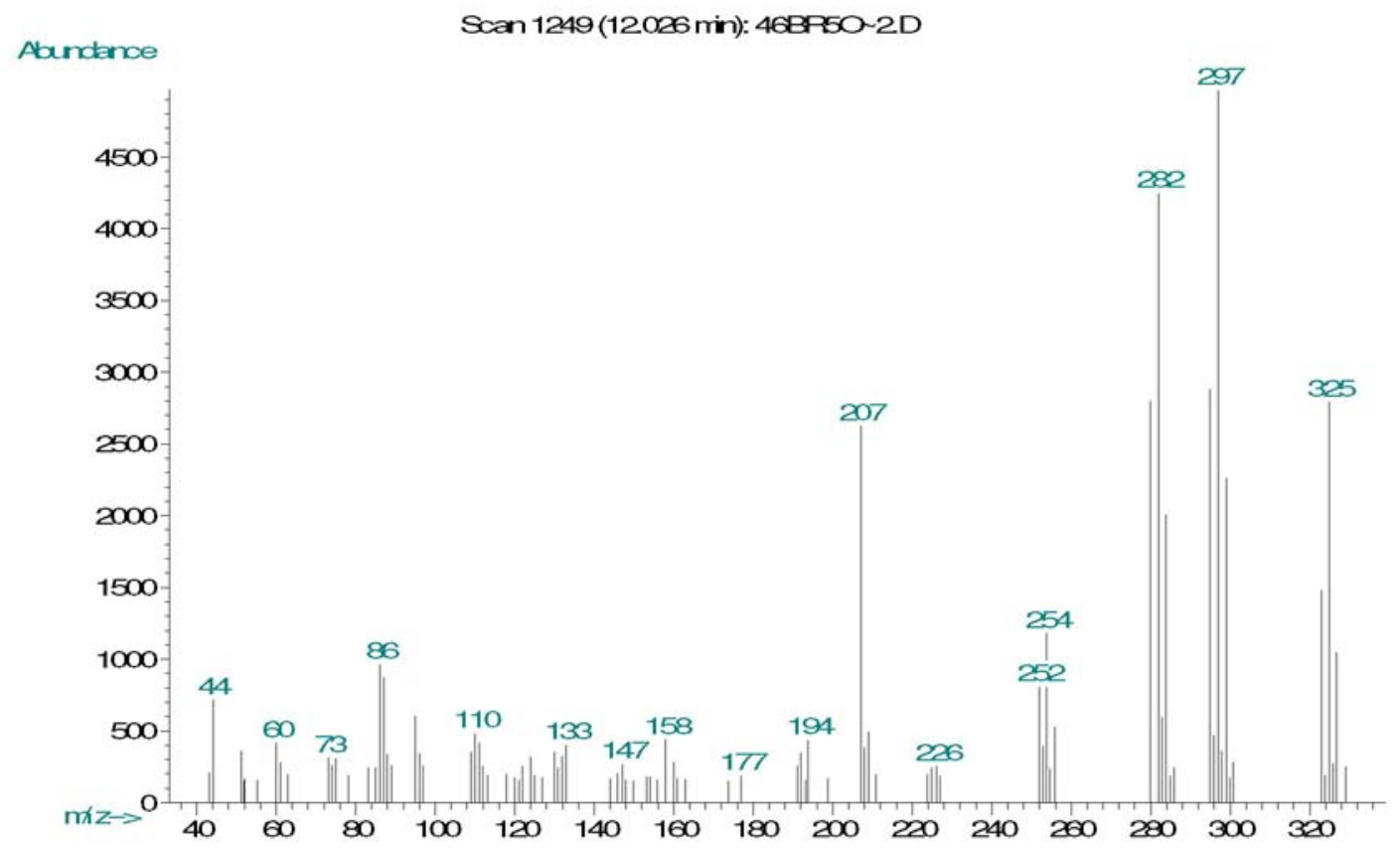

Figure S33. Mass spectrum of 8c. 


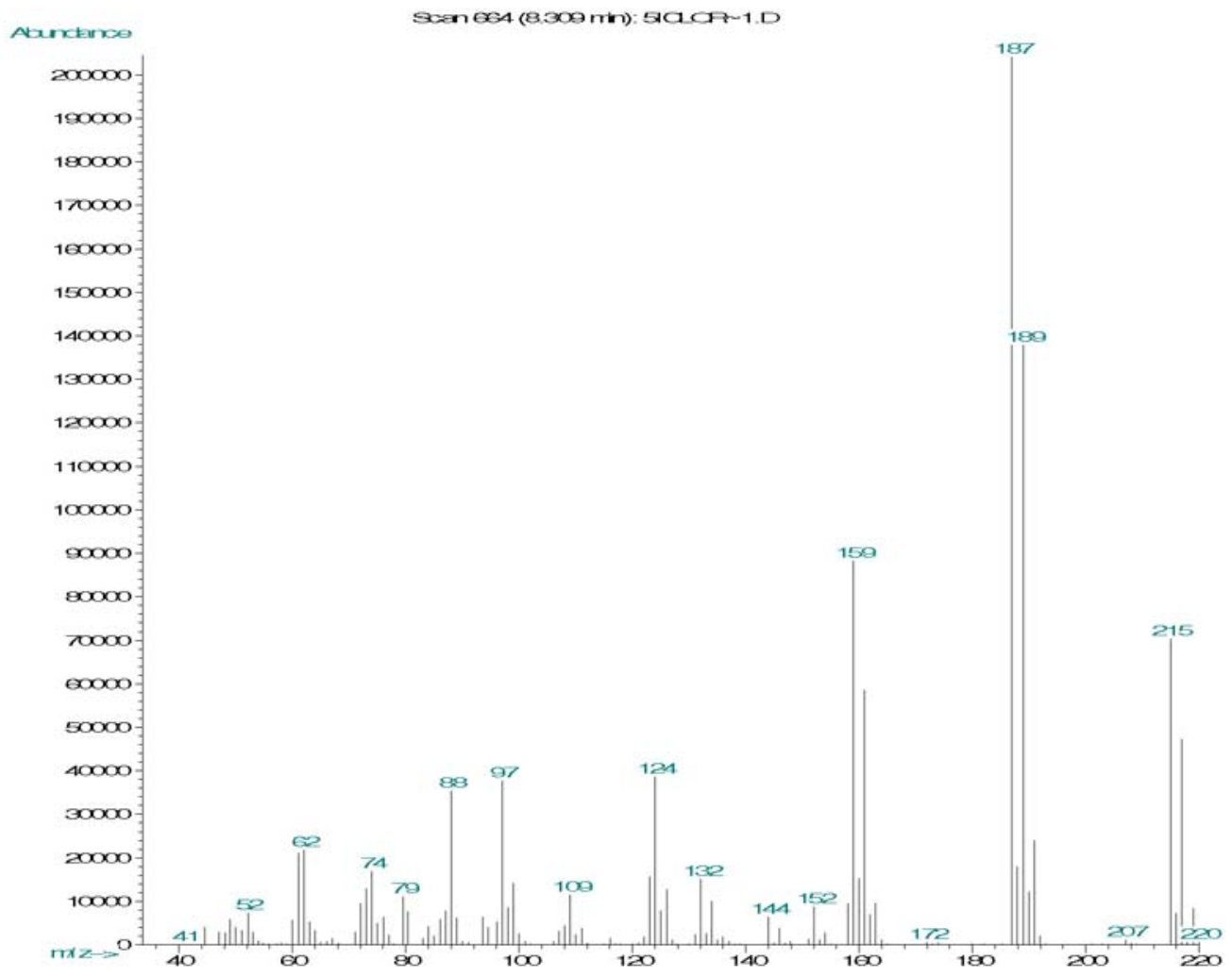

Figure S34. Mass spectrum of $\mathbf{9 b}$.

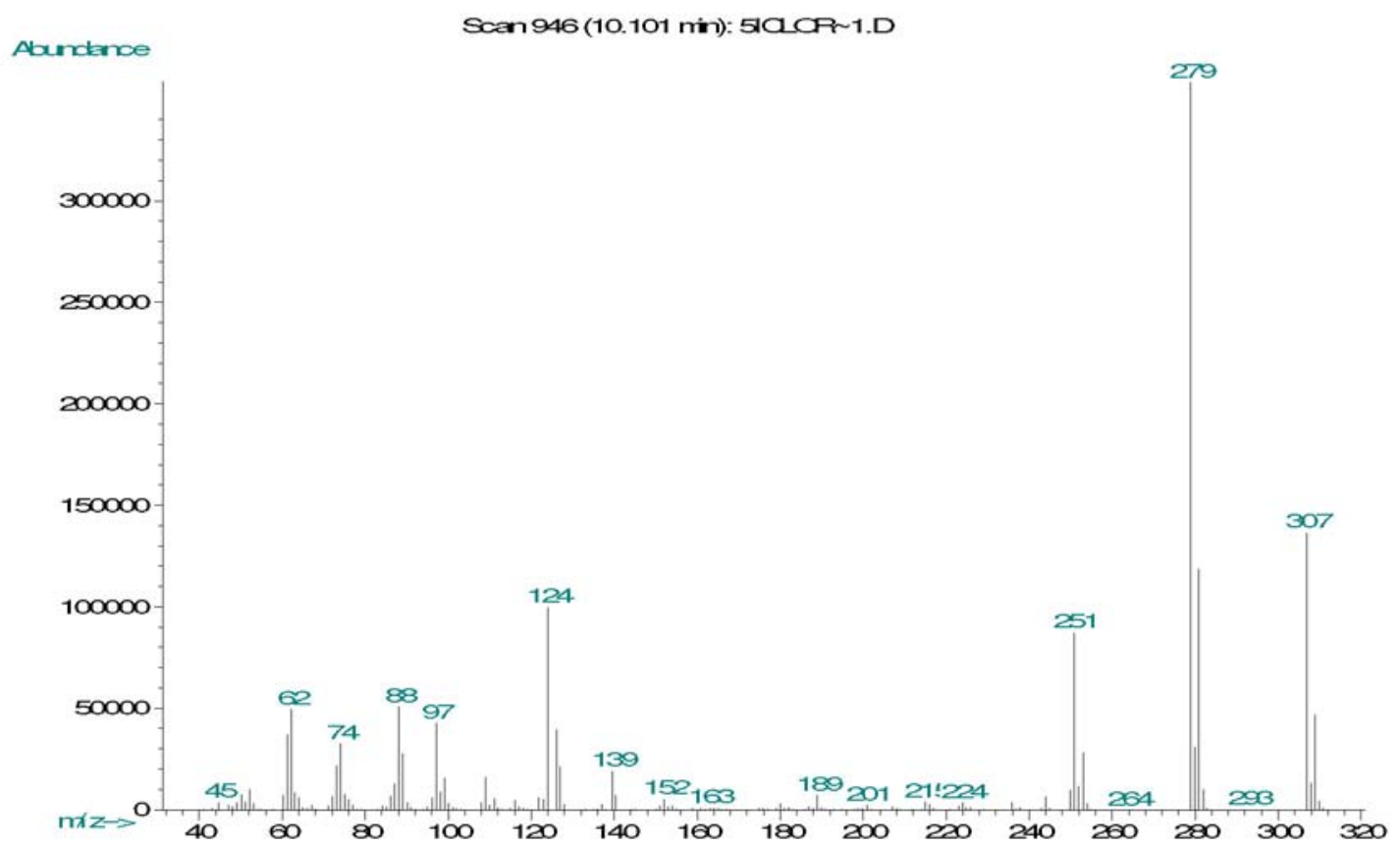

Figure S35. Mass spectrum of $\mathbf{9 c}$. 


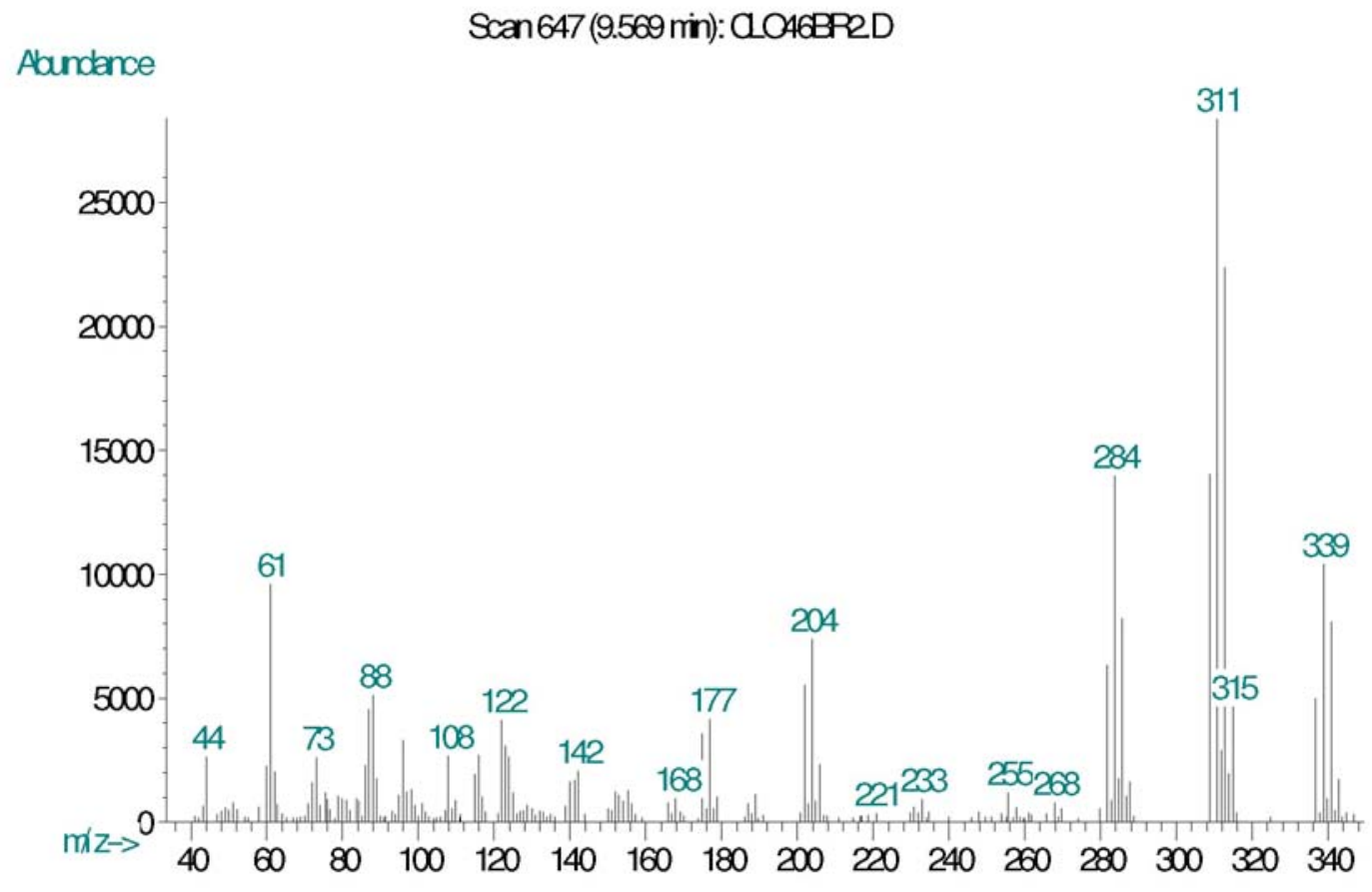

Figure S36. Mass spectrum of 11b.

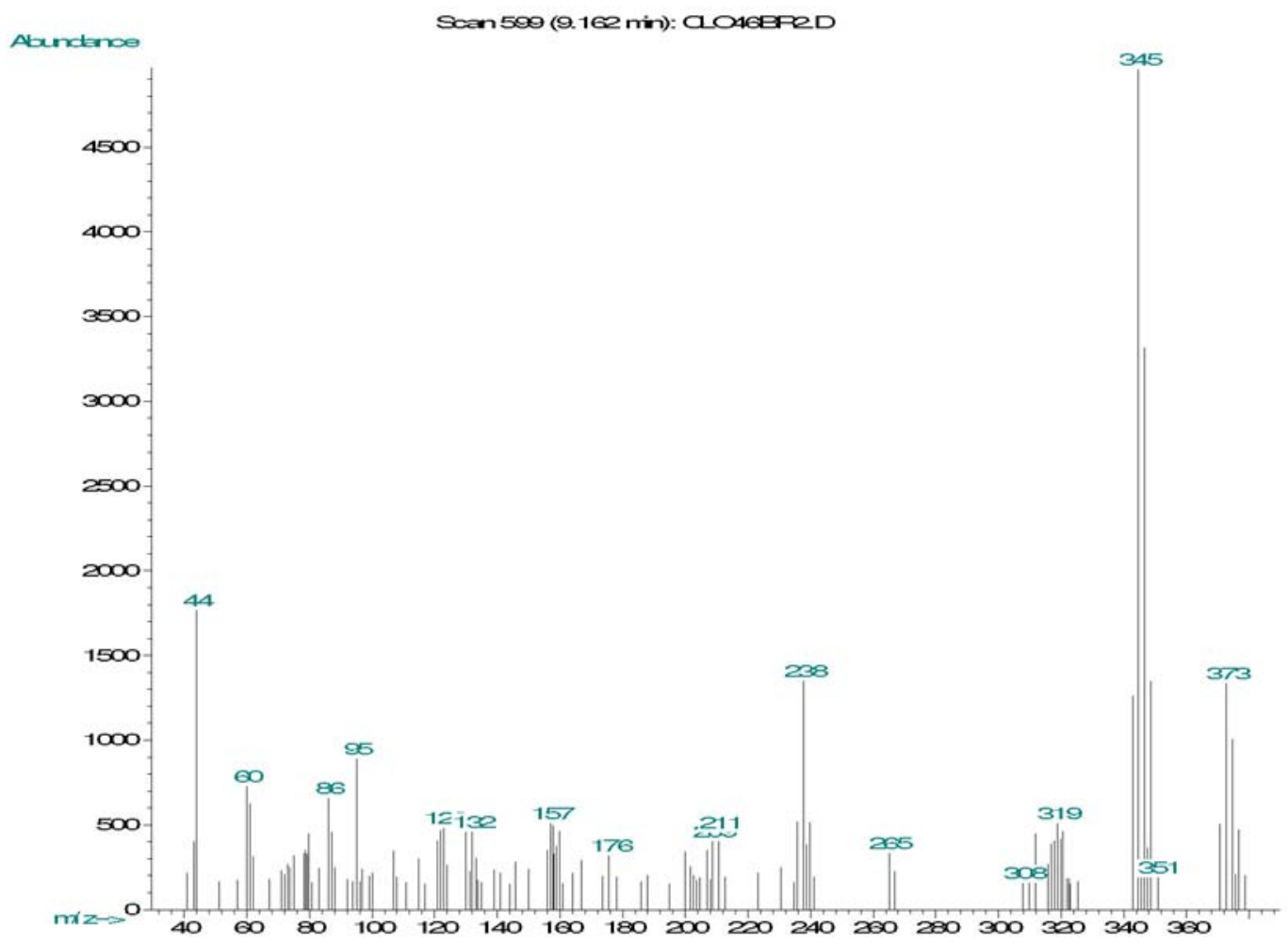

Figure S37. Mass spectrum of 11c. 